\title{
Interference-Free Electrochemical Detection of Nanomolar Dopamine Using Doped Polypyrrole and Silver Nanoparticles
}

Suparna Saha, Priyabrata Sarkar and Anthony Turner

\author{
Linköping University Post Print
}

Tweet

N.B.: When citing this work, cite the original article.

Original Publication:

Suparna Saha, Priyabrata Sarkar and Anthony Turner, Interference-Free Electrochemical Detection of Nanomolar Dopamine Using Doped Polypyrrole and Silver Nanoparticles, 2014, Electroanalysis, (26), 10, 2197-2206.

http://dx.doi.org/10.1002/elan.201400332

Copyright: Wiley-VCH Verlag http://www.wiley-vch.de/publish/en/

Postprint available at: Linköping University Electronic Press

http://urn.kb.se/resolve?urn=urn:nbn:se:liu:diva-112650 


\title{
Interference-free Electrochemical Detection of Nanomolar
}

\section{Dopamine Using Doped Polypyrrole and Silver Nanoparticles}

\author{
Suparna Saha, Priyabrata Sarkar*, Anthony PF Turner ${ }^{* *}$ \\ *Biosensor Laboratory \\ Department of Polymer Science and Technology \\ University of Calcutta \\ 92 A.P.C. Road, Kolkata-700 009, India \\ **Biosensors and Bioelectronics Centre \\ IFM-Linköping University \\ S-58183, \\ Linköping \\ Sweden
}

\begin{abstract}
:
Dopamine (3, 4-dihydroxyphenyl ethylamine, DA) is one of the most important neurotransmitters in the mammalian central nervous system. This paper presents a new approach to detect dopamine using an electrochemical sensor based on a composite made out of chitosan-stabilized silver nanoparticles and p-toluene sulfonic acid-doped ultrathin polypyrrole film, which exploits the synergy between the conducting polymer matrix and silver nanoparticles. These are characterized by TEM, XRD, UV-vis , FTIR, EDAX and the properties of the modified electrode is investigated by electrochemical impedance spectroscopy (EIS). The linear range is from $1 \times 10^{-9} \mathrm{M}$ to $1.2 \times 10^{-7} \mathrm{M}$ in $0.05 \mathrm{M}$ phosphate buffer ( $\mathrm{pH} 7.0$ ) with a correlation coefficient of 0.98 and an estimated detection limit of $0.58 \mathrm{nM}$ is obtained. A mechanism for the oxidation of DA on the modified electrode is proposed. High sensitivity of the composite layer towards DA, without interference from ascorbic acid (AA), uric acid (UA),
\end{abstract}


epinephrine, L-Dopa, glucose etc. are observed. Good reproducibility with a relative standard deviation of $6.3 \%$ and long-term stability of six weeks are also achieved. The utility of this method is demonstrated by quantitative determination of dopamine in commercially available human blood serum. Thus modified electrode shows excellent sensitivity, good selectivity and reusability at neutral $\mathrm{pH}$.

Keywords: dopamine, polypyrrole, silver nanoparticles, selectivity, impedance

\section{Introduction}

Dopamine (DA), the most important catecholamine, belongs to the family of excitatory chemical neurotransmitter. It plays an important role in the function of the central nervous, renal, hormonal and cardiovascular systems [1]. Deficiency or excess of DA may result in serious diseases related to neurological disorders, including Parkinson's disease and schizophrenia [2-4]. Since its discovery in the late $1950 \mathrm{~s}$ in the mammalian central nervous system, many attempts have been made to detect dopamine in biological samples such as blood serum or urine. Electrochemical techniques showed promise for the analysis of neurotransmitters in general, compared to fluorometric, radioenzyamatic, chromatographic, spectrophotometric and chemiluminescent techniques [5-8], since they offered direct measurement of the analytes. Non-electrochemical techniques involve withdrawing samples from the subject followed by rigorous separation, conditioning and other forms of sample pretreatment prior to analysis. Other advantages of electrochemical methods include high selectivity, good sensitivity and very low detection limits especially at microelectrodes [9]. However, early efforts to detect DA using metallic electrodes ran into several serious problems. Firstly, dopamine can be electro polymerized, leading to electrode fouling and degradation of response. Secondly, dopamine is commonly found in 
conjunction with other materials including its common oxidisable metabolites, and these generate substantial interference, as does the ubiquitously present ascorbic acid (AA). The third problem is that physiological concentrations of dopamine are very low, requiring very high selectivity and sensitivity $[7,10,11]$. In the extracellular fluid of the central nervous system, DA ranges from 0.01 to $1 \mu \mathrm{M}$ compared to $100-500 \mu \mathrm{M}$ of AA. Both DA and AA also exhibit nearly identical redox potential ranges and comparable sensitivities [8, 11, 12]. Thus, it has not been possible to detect DA selectively at conventional bare electrodes. Modified electrodes, on the other hand, may offer higher selectivity, sensitivity, time efficiency and higher stability. Therefore, several modifier materials such as Carbon nanotube [13, 14], polymers [15], nanoparticle-polymer [16-18], metal oxides [19], dye [20], Graphene [21], nafion [22], boron as dopant [23] have been used to overcome this problem.

Conducting polymers have attracted much interest due to their high conductivity, ease of preparation, good environmental stability and large variety of applications in light emitting, electronic devices, chemical sensors, separation membranes and antistatic coating [24-26]. Among various types of conducting polymers, polypyrrole has many attractive features as molecular recognition system [27, 28]. Deposition of a conducting polymer is a simple approach to construct a sensor electrode. The advantages of electropolymerisation are: (a) thin, uniform and adherent polymer films can be obtained; (b) films can be deposited on a small surface area with a high degree of geometrical conformity and controllable thickness using a specific number of growth cycles in potentiodynamic cycling[29, 30].

Metal nanoparticles have electronic, optical and magnetic properties different from those of the bulk materials. Electrodes modified by metal nanoparticles usually exhibit high electrocatalytic activities towards the compounds which otherwise have sluggish redox process at bare electrodes [31]. The synthesis of silver nanoparticles with precise particle size and shape is a challenge. Generally, metal nanoparticles aggregate among themselves and progressively grow into larger clusters and eventually precipitates, deviating from nanoscale. This reduces the effectiveness of synthesized nanoparticles and 
discourages their application [32]. Coalescence may be prevented by adding a polymeric stabilizer. Synthetic polymers such as polyvinyl chloride (PVC), polyvinyl alcohol (PVA) and polyvinyl pyrrolidone (PVP) have been used as stabilizing polymers of silver nanoparticles (AgNPs) [33]. Due to the non-biodegradability and toxicity of synthetic polymers, natural polymers have been given a considerable attention to stabilize the AgNPs. Hence, natural polysaccharides being environmentally benign, biodegradable, highly abundant and of low cost, are preferred as a stabilizers for synthesized AgNPs [34].

In this paper, we report a modified electrode prepared by electropolymerising pyrrole on platinum electrode with p-toluene sulfonic acid dopant followed by a coating of chitosan stabilized silver nanoparticles. Presently, there is no reported work for the selective determination of DA using silver nanoparticles and polypyrrole modified platinum electrode. The modified electrode was utilized as the sensing matrix for the selective determination of DA at nanomolar levels in human blood serum samples and might be useful for the diagnosis of Parkinson's disease.

\section{Experimental}

\subsection{Reagent and Chemicals:}

Chitosan (88\% deacetylation), silver nitrate, p-toluene sulfonic acid (PTSA) were purchased from Himedia (India). Pyrrole, dopamine (DA), epinephrine (EP), uric acid (UA) were supplied by Sigma Aldrich (USA) and used as received. Ascorbic acid (AA), aspartic acid, L-Dopa, glucose were of analytical reagent grade and purchased from EMerck, Germany. A 50mM phosphate buffer solution was used to control the $\mathrm{pH}$. Aqueous solutions were prepared by Milli-Q (MQ) water. All experiments were conducted at room temperature. Human blood serums were supplied by Medicave diagnostic centre, Kolkata, India. These were stored in a $-80^{\circ} \mathrm{C}$ freezer. 


\subsection{Instruments:}

Cyclic Voltametry (CV) and Differential Pulse Voltametry were performed using an AUTOLAB, PGSTAT 30 with GPES software (version 4.9) in a conventional three-electrode system with a bare or modified working $(\mathrm{Pt})$ electrode (surface area $0.64 \mathrm{~cm}^{2}$ ), a platinum wire counter electrode and an $\mathrm{Ag}$ $\mathrm{AgCl}$ reference electrode.

The ac impedance analysis was performed with AUTOLAB, PGSTAT 12 9(Eco Chemie, The Netherlands) with a frequency response analyser (version 4.9). The impedance measurements were run at a potential of $200 \mathrm{mV}$ with $5 \mathrm{mV}$ (rms) sinusoidal excitation amplitude. A solution of $50 \mathrm{mM}$ phosphate buffer ( $\mathrm{pH} 7)$ was used as the electrolyte in a three-electrode cell, as mentioned above. All measurements were performed at room temperature $\left(22-24^{\circ} \mathrm{C}\right)$ over the frequency range 0.1 to $10^{5} \mathrm{~Hz}$, number of frequency 50 and then data were analysed by using NOVA-1.9 software.

The bulk morphology and particle size of silver nanoparticle was studied by TEM using a Technai G2 Spirit Bio Twin instrument (USA). The spectra were taken against air at $30{ }^{\circ} \mathrm{C}$ in a UV-vis spectrophotometer (CECIL CE7200, 7000 series, UK) from 200 to $600 \mathrm{~nm}$. The surface morphology of the nanoparticles and polymer matrix was characterised by scanning electron microscopy (FEI quanta 200, USA) at $20 \mathrm{kV}$ and different magnification. The FTIR spectra of samples were performed in a Thermo Scientific FTIR instrument (Model Nicolet iS 10,) using ATR sampling technique. The spectra over the range $4000-400 \mathrm{~cm}^{-1}$ were obtained at a resolution of $4 \mathrm{~cm}^{-1}$. WAXS (Wide angle X-ray Scattering) was performed using XPERT-PRO wide angle X-ray diffractometer (USA) in reflection mode. The instrument was operated at a $40 \mathrm{kV}$ voltage and a $30 \mathrm{~mA}$ current using $\mathrm{Ni}$ filtered $\mathrm{Cu}-\mathrm{k} \alpha$ radiation $(\lambda=1.54 \mathrm{~A})$. The samples were scanned from $2 \theta=20-90^{\circ}$ in the step scan mode to record the diffraction pattern. 


\subsection{Synthesis of silver nanoparticles:}

Silver nanoparticles were prepared following a green route using chitosan as a reducing agent. Chitosan (1.25 wt \%) solution was prepared in $1 \%(\mathrm{wt})$ acetic acid solution. The freshly prepared $0.4 \mathrm{mM}$ $\mathrm{AgNO}_{3}$ solution $(1 \mathrm{ml})$ was added drop wise at $95^{\circ} \mathrm{C}$ through a dispenser followed by addition of 100 $\mu \mathrm{L}$ of $0.3 \mathrm{M} \mathrm{NaOH}$ in continuous stirring condition. After few minutes, resultant solution started turning yellow indicating the formation of $\mathrm{AgNP}$ in the medium. The reaction was allowed to continue for additional 30 minutes and it finally turned brown and the powdered nanoparticles settled at bottom of the beaker. The solid particles were separated by centrifugation and later washed several times with (MQ) water. This was then air dried and stored. The filtrate was treated with concentrated $\mathrm{HCl}$ to check if there were any excess of $\mathrm{Ag}^{+}$remaining in the reaction medium. This test however confirmed that the whole of $\mathrm{AgNO}_{3}$ got reduced to $\mathrm{Ag}$ nanoparticles.

\subsection{Preparation of polypyrrole film-modified platinum electrode:}

Prior to modification, the bare Pt electrode was polished using alumina slurries and ultrasonicated in ethanol and MQ water for five minutes. Electrochemical polymerisation of pyrrole was carried with $0.1 \mathrm{M}$ pyrrole in $0.1 \mathrm{M}$ PTSA solution by cycling the potential from $-0.35 \mathrm{~V}$ to $0.85 \mathrm{~V}$ at a scan rate of $30 \mathrm{mv} / \mathrm{s}$ for five cycles. Polymer film formed by less than 5 cycles was found to be unstable and hence doping agent could not be adequately embedded. On the other hand, a higher number of cycles led to the formation of thicker film with less accessible areas for doping. The electrode was rinsed with MQ water and treated with $0.1 \mathrm{M} \mathrm{NaOH}$ before running $\mathrm{CV}$ five times to form overoxidise doped polypyrrole (PPyox-PTSA). After a final wash with water, the electrode was modified with AgNPs; $10 \mu \mathrm{l}$ of chitosan stabilized Ag nanoparticles $(5 \mathrm{mg} / \mathrm{ml})$ was dispensed onto the modified electrode and dried at room temperature. This modified electrode was denoted as PPyox-PTSA/Ag-NP/Pt. 
2.5 Measurements of response: The Optimum $\mathrm{pH}$ for the detection of dopamine was first determined by varying the $\mathrm{pH}$ from 5 to 9 . Subsequent cyclic voltammetry experiments were conducted at this $\mathrm{pH}$ and at room temperature to determine the optimum scan rate by varying the rate from $10-150 \mathrm{mVs}^{-1}$. The performance of unmodified, PPyox-PTSA modified and PPyox-PTSA/Ag-Np modified platinum electrodes for $1 \mathrm{mM}$ dopamine was investigated by cyclic voltametry in $50 \mathrm{mM}$ phosphate buffer at optimum $\mathrm{pH}$ and various scan rates. The effect of probable interfering substances which are present in blood serum was also studied by amperometry at a constant potential of $0.25 \mathrm{v}$. For the stability and reusability study, the response current was measured over a period of 7 weeks of storage with measurement of response every 7 days for 10mM DA solution, using the same modified electrode in 50mM Phosphate buffer solution ( $\mathrm{pH} 7$ and at $40 \mathrm{mVs}^{-1}$ scan rate)

\section{Results and Discussion}

\subsection{Characterisation of silver nanoparicles and polypyrrole film}

The morphology of chitosan stabilized silver nanoparticles was observed by transmission electron microscopy (TEM) (Fig. 1a). This clearly revealed the formation of individual silver nanoparticles. The nanoparticles were predominantly spherical and polydispersed, with diameters in the range of 20 to 25 nm.

A sample of yellow powder of the composite was dispersed in $0.1 \%(\mathrm{~V} / \mathrm{V})$ of acetic acid and the UVvisible spectrum was recorded. The characteristic band of Ag nanoparticles centered at about $420 \mathrm{~nm}$ (Fig. 1b). Chitosan stabilized AgNP could be stored up to several months without any discernible precipitation.

The X-ray diffraction pattern of pure chitosan (Fig. 1c) showed weak bands at $2 \theta$ values of $20.35^{\circ}$, indicating the mostly amorphous nature of the chitosan used in the present study. In the diffractograms 
of the chitosan-Ag samples (See supporting information) the additional peaks appeared at $2 \theta$ with values of around $36^{\circ}(111), 45^{\circ}(200), 55,66(220)$, and $77^{\circ}$ and could be recognized as $111,200,220$, and 311 crystallographic planes of the face-centered cubic Ag crystals, respectively. The peaks confirmed that the main composition of nanoparticles was silver and no other obvious peaks due to the presence of impurities were observed in the XRD patterns. The peak at 22.71 could be due to chitosan with somewhat deviation from $20^{\circ}$ of pristine chitosan. The existence of silver nanoparticles in the chitosan fragment was substantiated by this result.

In FTIR spectra (Fig. 2a) the absorption peak at 3437 resulted from the $\mathrm{C}-\mathrm{H}$ and $\mathrm{N}-\mathrm{H}$ stretching vibration of PPy film without dopant. Another feature in the FTIR spectrum was the skeletal stretching in the pyrrole ring, which occurred in the region of 1550 and 1458. The bands at 1312 and 1030 might correspond to the $=\mathrm{C}-\mathrm{H}$ in plane vibration, while the $-\mathrm{C}-\mathrm{H}$ out of plane vibration was found at 889 indicating polymerisation of pyrrole [35]. Fig. 2b describes the FTIR spectra of doped over-oxidised polypyrrole with p-toluene sulfonate. Due to doping by PTSA the N-H band (3400) of the pyrrole ring was not observed in the spectrum. The band at 1186 was due to stretching vibration of the group in PTSA anion demonstrating that dopant anion was present in the polymer backbone. The peak at 913 could be attributed to the stretching vibration of the doped pyrrole, indicating successful polymerisation of the PPy films. The most obvious change of FTIR spectra after the over-oxidation was the appearance of a new peak at 1680 , which indicated that $\mathrm{C}=\mathrm{O}$ was introduced into the polymer backbone during over-oxidation. Thus FTIR results confirmed doping as well as over-oxidation of polypyrrole film during electropolymerisation.

In Fig. 3A, the surface morphology of electro polymerised PPy film showed its characteristic smooth surface, whereas the PPyox-PTSA (Fig. 3B) film exhibited a 'cauliflower' morphology typically seen with the dopant PTSA [36]. However, its morphology seemed to be more structured and organised and not normally observed with a characteristic PPy film. The morphology of the PPy films displayed 
micro-spherical grains; the size of most of the grains was about 7 to $10 \mu \mathrm{m}$. The SEM image of porous, overoxidized PPy-PTSA film is shown in Fig. 3C).

\subsection{Electropolymerisation of pyrrole at platinum surface}

Cyclic voltammograms of $0.1 \mathrm{M}$ pyrrole in presence of $0.1 \mathrm{M}$ PTSA at platinum electrode was done to electro deposition of polypyrrole on the Pt electrode. The oxidation peak appeared at $0.19 \mathrm{v}$ and reduction peak at $-0.30 \mathrm{v}$. The surface coverage, $\Gamma$ of the electrode due to electropolymerisation was evaluated using the following equation [37]

$$
\Gamma=\mathrm{Q} / \mathrm{nFA}
$$

Where $\mathrm{n}$ is the number of electrons transferred during redox reaction, $\mathrm{F}$ is Faraday constant, $\mathrm{A}$ is surface area of electrode and Q is charge obtained by integrating the anodic peak under background correction at a low scan rate. This was found to be $9.6 \times 10^{-9} \mathrm{~mole} / \mathrm{cm}^{2}$. The clear and well defined redox peaks of PPy/PTSA corresponded to dopant incropration in polymer matrix.

\subsection{Characterization of PPyox-PTSA/Ag NP/ Pt electrode by electrochemical impedance spectroscopy}

Electrochemical impedance spectroscopy (EIS) is a powerful technique which provides useful information due to change in input frequency and thus allows the measurement of impedance of electrochemical system before and after any redox reaction and predicts equivalent electrical circuit of modified electrodes. This study was carried out in $0.1 \mathrm{mM}$ DA at $\mathrm{pH} 7$, phosphate buffer using

modified electrode. The Nyquist plot (Fig. 4) shows that electron-transfer resistance $\left(\mathrm{R}_{\mathrm{ct}}\right)$ value of PPyox-PTSA/ Ag NP/ Pt (as a quasi-straight line) was much lower than that of the bare Pt, which was 
attributed to the high conductivity of the PPyox-PTSA/ AgNP films that facilitated fast electron transfer between the solution and the electrode interface. The Nyquist plots included distinct semicircular and a linear parts. The semicircular part, which appears at higher frequencies, corresponds to the electron transfer limited process and the diameter of this part is equivalent to the electron transfer resistance (Rct). The linear part, which appears at lower frequencies, corresponds to the diffusionlimited process. Initial Rct value for the bare-Pt was $2.19 \mathrm{~K} \Omega$ while it increased to $5.62 \mathrm{k} \Omega$ after the electropolymerisation, but again decreased after oxidation or doping. Considerable increase in Rct was observed due to the increase in thickness of the PPy-modified electrode compared to the bare Pt electrode. This behaviour showed that the electron transfer to the electrode was significantly reduced due to the presence of the electropolymerised PPy film without doping agent PTSA. The change of Rct was obvious after oxidation or introduction of PTSA, since the number of negatively charged (carboxyl, carbonyl, hydroxyl and sulfonate ion) groups localised on the Pt electrode surface increased on oxidation. These groups attracted the positively charged ions (DA) toward the electrode surface and thus facilitated the electron transfer. After the modification of the Pt electrode with Ag NP, the Rct value decreased markedly and it reached $20.8 \Omega$. This electron transfer reaction on modified electrode surfaces is in agreement with the standard Randles equivalent circuit model in the high frequency range. The equivalent circuit included the solution resistance (Rs), the charge transfer resistance (Rct), the Warburg resistance (Wo) and the constant phase element (CPE).

In order to calculate the electron transfer rate constant, $\mathrm{k}_{0}$ (data shown in Table 1), for the redox reaction of DA for differently modified electrodes, Equation (2) [38] was applied.

$\mathrm{R}_{\mathrm{ct}}=\mathrm{RT} /(\mathrm{nF})^{2} \mathrm{Ak}_{0} \mathrm{C}$

where $\mathrm{A}$ is the electrode area; $\mathrm{n}$ is the number of electrons requested for the reduction/oxidation of DA ions; $\mathrm{C}$ is the molar concentration $\mathrm{DA} ; \mathrm{R}$ is ideal gas constant, $\mathrm{T}$ is the temperature in Kelvin; $\mathrm{F}$ is the Faraday constant. 


\subsection{Effect of pH}

The effect of the electrolyte $\mathrm{pH}$ on the response of DA was investigated over the $\mathrm{pH}$ range 5-9. Fig. 5 shows that the anodic peak current increased with increasing $\mathrm{pH}$ up to 7 and started decreasing at $\mathrm{pH}>$ 7. With increasing $\mathrm{pH}$ the negative sulfonate group on electrode surface started attracting DA cations to the electrode surface. Thus the anodic peak current for DA increased with increasing $\mathrm{pH}$ over the range 5-7. Above $\mathrm{pH} 7$, the degree of protonation of DA decreased, since the hydroxy group of DA could be easily oxidised under alkaline conditions. Although there was an increase in the concentration of negative sulfonate groups on the electrode surface, the decrease in DA cations resulted in less interaction between DA and the polymer film. The anodic peak current of DA decreased with increasing $\mathrm{pH}$ over the range 7.5-9. The optimum $\mathrm{pH}$ for electrochemical detection of DA was chosen as 7.0, since this yielded the maximum current response and the blood serum could be directly analysed without adjustment of the $\mathrm{pH}$. In addition, the peak potential ( $\left.\mathrm{E}_{\mathrm{pa}}\right)$ shifted negatively with increasing $\mathrm{pH}$, indicating the active role of protons.

In phosphate buffer, $\mathrm{pH}$ 7.0, DA exists as a cation with a positively charged amino group (pKa 8.9) [39] while PTSA is non-protonated. Hence, the oxidation of DA might be ascribed to the electrostatic attraction interaction between DA cations and the high electron density of sulfonic group of PTSA. The formal potential (Ea' value was taken as the average value of the anodic and cathodic peak potentials) of the surface redox couple was pH-dependent (inset of Fig. 5). The slope of anodic potential Epa vs. $\mathrm{pH}$ was evaluated to be $49 \mathrm{mV} / \mathrm{pH}$ unit, which was very close to the anticipated Nernstian value for a two-electron, two-proton process [40]. A linear regression analysis Epa $=0.447-0.049 \mathrm{pH}$ (correlation coefficient, $R^{2}=0.987$ ) showed that the uptake of electrons was accompanied by an equal number of protons. 


\subsection{Effect of scan rate on DA oxidation and kinetic analysis}

The influence of scan rate on the response of DA with the polymer-modified electrode was investigated by cyclic voltammetry (Fig. 6). The voltammogram response at different scan rates could reveal kinetic information concerning the electrocatalytic process, such as diffusion and adsorption effects.

Both the values of anodic peak current (Ipa) and cathodic peak current (Ipc) exhibited a linear relationship with the square root of the scan rate. The linear regression equations $\operatorname{Ipa}(\mu \mathrm{A})=51.86 \mathrm{v}^{1 / 2}$ $\left(\mathrm{mVs}^{-1}\right)^{1 / 2}-5.047\left(\mathrm{R}^{2}=0.98\right)$ and Ipc $=-51.87 \mathrm{v}^{1 / 2}\left(\mathrm{mVs}^{-1}\right)^{1 / 2}-4 / 192\left(\mathrm{R}^{2}=0.986\right)$, respectively (inset of Fig. 6) implied that the electro catalytic reaction was diffusion controlled. As the plot of the peak current against the square root of the scan rate yielded a straight line (inset of Fig. 6) with similar slopes for Ipa $\mathrm{Vs}^{1 / 2}$ and Ipc $\mathrm{Vs}^{1 / 2}$, an equimolar counter diffusion process could be predicted. Hence the system was ideal for quantitative analysis in practical applications. Furthermore, the Randles-Sevcik equation [41], which is limited to reversible processes, also described the factors that influence the magnitude of peak current.

$$
\mathrm{ip}=\left(2.69 \times 10^{5}\right) \mathrm{n}^{3 / 2} \mathrm{D}^{1 / 2} \mathrm{~A} \mathrm{v}{ }^{1 / 2} \mathrm{C}_{0}
$$

In Equation 3, ip is the peak current $\left(\mathrm{A} \mathrm{cm}^{-2}\right), \mathrm{n}$ is the electron stoichiometry, $\mathrm{D}$ is the diffusion coefficient $\left(\mathrm{cm}^{2} \mathrm{~s}-1\right)$, A is surface area of electrode $\mathrm{v}$ is the scan rate $(\mathrm{V} \mathrm{s}-1)$ and $\mathrm{C}_{0}$ is the concentration $\left(\mathrm{mol} \mathrm{cm}{ }^{-3}\right)$. Thus the diffusion coefficient could be determined from the slope of any this straight line.

The calculated value of diffusion coefficient from this equation was $4.5 \times 10^{-5} \mathrm{~cm}^{2} \mathrm{~s}^{-1}$, which compared well with values reported in literature [42], i.e. $6.6 \times 10^{-6} \mathrm{~cm}^{2} \mathrm{~s}^{-1}$ to1.5 $\times 10^{-5} \mathrm{~cm}^{2} \mathrm{~s}^{-1}$.

It was also observed that with increasing scan rate, both the anodic and cathodic peak current increased, but the position of the peak voltage did not change, conforming to the characteristics of electrode reactions having rapid electron transfer kinetics. 


\subsection{Electrochemical oxidation of DA on modified electrode}

With a bare Pt working electrode, DA showed a pair of redox waves with the anodic and cathodic peaks at $624 \mathrm{mV}$ and $140 \mathrm{mV}$, respectively. However no voltammetric response was observed after the addition of DA with a PPyox-PTSA/Pt working electrode. This was due to the resistance of the insulating PPyox film, which caused blockage of direct electron transfer and mass transport. In the case of the PPyox-PTSA/Ag-NP/Pt, the redox peak potentials shifted to $210 \mathrm{mV}$ and $-142 \mathrm{mv}$ (Fig. 7), and the peak current was enhanced by about 3 times compared to the bare Pt. This might be attributed to the $\mathrm{Ag}$ nanoparticles on polymer-modified electrode providing larger effective surface area than the bare electrode and hence higher catalytic efficiency. The peak characteristics clearly indicated an electrocatalytic oxidation of DA at PPy-modified electrodes resulting from a more active surface compared to the bare Pt. The electrochemical response indicated by the redox peak current, increased with increasing analyte concentration (Fig. 8). The anodic peak current produced a linear plot with DA concentration in the range $10 \mathrm{nM}$ to $120 \mathrm{nM}$ (Inset of Fig. 8) and the linear regression equation is $\mathrm{y}=$ $0.0292 x+0.205$ The limit of detection (LOD) and limit of quantification (LOQ) of DA determination were calculated from the following relations [43].

$$
\begin{aligned}
& \mathrm{LOD}=3 \mathrm{~S} / \mathrm{m} \\
& \mathrm{LOQ}=10 \mathrm{~S} / \mathrm{m}
\end{aligned}
$$

Where $\mathrm{S}$ is the standard deviation and $\mathrm{m}$ is the slope of calibration plot. These were found to be $0.58 \mathrm{x}$ $10^{-9} \mathrm{M}(\mathrm{LOD})$ and $1.97 \times 10^{-9} \mathrm{M}$ (LOQ) respectively. The sensitivity calculated from the slope of the calibration plot was found to be $0.0292 \mu \mathrm{A} / \mathrm{nM}$ [44]. It could be seen that the oxidation peak potential of dopamine shifted slightly towards positive potential with increase in concentration (Fig.8) of DA. This might be due to coupling of electron transfer reaction to chemical reaction (ECE) in dopamine oxidation mechanism. In ECE mechanism, DA first diffuses onto the working electrode and releases electrons which are accepted by the working electrode while forming dopamine-O-quinone (DAQ). In 
the reverse scan o-quinone captures electrons from the electrode to form dopamine. However, as per the following mechanism (Scheme1) DAQ may undergo chemical reaction to form leucodopaminechrome (LDAC) via intramolecular 1,4 dipolar addition and this could further get oxidized to dopaminechrome (DAC) through a two electron transfer reaction. According to La Chatelier's principle the equilibrium of dopamine oxidation reaction should shift to the right hand side i.e more towards the DAQ with increase in DA concentration. In spite of the reversible nature of this reaction, a part of DAQ undergoes a side reaction to form DAC which has a tendency to form melamine like polymer on the electrode surface resulting in inhibition of the electron transfer on the electrode. Hence the system would require higher potential for the oxidation reaction. Simultaneously one would expect reduction in the cathodic peak current during reverse scan due to non-availability of equilibrium concentration of DAQ on the electrode because of this side reaction. The results supported this theory and produced Ipc/Ipa less than unity (0.714).

\subsection{Interference Study}

The most important issue in dopamine detection is the interference due to the presence of other electro active species which coexist at higher concentration than DA in the serum fluids and have similar redox potentials. As anticipated, the bare Pt electrode exhibited comparable response signals for AA, UA, DA, epinephrine (EP), aspartic acid, L-dopa, glucose, and DA at their physiological levels, thus generating significant potential interference. Fig. 9 shows the signal response of PPyox-PTSA/Ag$\mathrm{NP} / \mathrm{Pt}$ electrode at $0.25 \mathrm{~V}$ with sequential addition of $100 \mu \mathrm{M}$ AA, $50 \mu \mathrm{M}$ UA, $50 \mu \mathrm{M}$ EP, $50 \mu \mathrm{M}$ aspartic acid, $50 \mu \mathrm{M}$ L-Dopa, $10 \mu \mathrm{M}$ DA. The current responses generated due to these interfering species were negligible, indicating the high selectivity of the sensor. 


\subsection{Selective electrochemical response for AA, DA and UA by modified electrode:}

In the extra-cellular fluid of the central nervous system and serum, AA and UA coexist with DA. They exhibit almost same oxidation potential as DA. Thus it is essential to detect DA selectively avoiding any interference from these coexisting molecules. The ability of this PPyox-PTSA/Ag-NP/Pt modified electrode to promote the voltammetric resolution of DA, AA, and UA was investigated by Differential Pulse voltammetry. The bare Pt exhibited a rather broad oxidation peak and the indistinguishable peak potentials of AA, DA and UA (Fig. 10A). The individual components could not be determined from the merged voltammetric peak and hence by constant potential amperometry. The voltammetric responses of a mixture of $100 \mu \mathrm{M}$ AA, $0.1 \mu \mathrm{M}$ DA and $50 \mu \mathrm{M}$ UA at PPyox-PTSA/Ag-NP modified Pt in pH 7.0 PBS, on the other hand, showed distinct individual oxidation peaks as at potentials around $-0.19,0.21$ and $0.61 \mathrm{~V}$ for AA, DA and UA, respectively. Since AA exists as anions in $\mathrm{pH} 7.0 \mathrm{PBS}$, electrostatic repulsion between the AA anions and the negative sulfonic groups at the modified electrode surface retarded the electron transfer and thus shifted the oxidative potential of AA toward more negative value, separating the oxidative peak of DA. The separation of the oxidation peak potentials for AADA, DA-UA and AA-UA are about 400, 400 and $800 \mathrm{mV}$. This separation was large enough to achieve the simultaneous determination of these three compounds in a homogeneous solution.

In addition, various concentrations of DA in the presence of $100 \mu \mathrm{M} A \mathrm{~A}$ and $50 \mu \mathrm{M}$ UA exhibited excellent DPV responses without any obvious intermolecular effects. The peak current of DA increased linearly with increasing DA concentration (Fig. 10B). We also examined the influence of AA and DA on the oxidation of UA under the optimum conditions at $\mathrm{pH} 7.0$ using the modified Pt electrode. No change was observed in the DA peak currents with varying the AA and UA strength. In addition, the oxidation peak current of AA and UA increased linearly (Fig. 10C and 10D). These results indicate that the modified electrode could be suitable for the simultaneous determination of these three 
compounds without observing any interference from each other. The observed good selectivity might be attributed to the negative surface charge and functional groups (e.g. $-\mathrm{NH}$ or $\mathrm{OH}$ ) of the PPy film, which could provide an excellent selective interface for the detection of DA.

\section{Stability and reproducibility}

For monitoring of dopamine in real samples, stability and reusability are normally important factors. However, for one-off measurements, these are of little importance, especially when the preparation of the modified electrode is easy and rapid and the whole measurement procedure takes only 15 minutes. Even so, it was observed (Fig. 11a) that over the first 7days the oxidation of DA signal decreased only by $1.1 \%$ and the oxidation current response maintained $93.7 \%$ of the original peak current even at the end of the $7^{\text {th }}$ week.

In order to examine the reproducibility of the modified electrode, repeated cyclic voltammetry experiments were performed with a modified electrode in $1 \mathrm{mM}$ DA in 50mM pH 7 phosphate buffers. No significant change in the peak potential and the current response was observed (Fig. 11b). The relative standard deviations (RSD) in voltammetry responses for 10 measurements for 1mM DA were less than 5\%, indicating excellent reproducibility of the fabrication method.

\section{Real Sample analysis by constant potential amperometry}

Abnormal concentrations of DA in body fluids influence the function of central nervous system. Hence the modified electrode was used to measure DA content in spiked serum samples without any pretreatment under the previously described optimal experimental conditions by amperometry at $0.25 \mathrm{~V}$. The calibration curve of Fig. 12 shows the steady state current response for DA of known 
concentrations at the PPy/PTSA/Ag. The nearly equal current steps for each addition of DA demonstrated stable and efficient catalytic activity of the electro catalyst i.e. AgNP immobilized in the polymer film. A linear relationship $(y=4.252 x+2.051)$ between DA oxidation peak current and concentration was obtained in the concentration range of $0.01 \mu \mathrm{M}$ to $1 \mu \mathrm{M}$ with a correlation coefficient of 0.98 .

In order to evaluate the accuracy of the method while detecting DA in serum samples, these (having no DA initially) were spiked with dopamine in various known concentrations. Using the linear equation already derived from the standard curve, the concentrations of DA in blood serums were determined and compared with actual concentrations. The recovery rates for dopamine were determined in the range $94-100 \%$ and the results are summarized in Table 2. The recoveries indicate that the accuracy of the proposed method was excellent.

\section{Comparison of results}

The performance of this newly developed sensor was compared with published data on dopamine sensors and consolidated in Table 3. It can be seen that the sensor achieved the highest sensitivity and lowest detection time (9s). Many of the previously published papers have not reported on the effect of interfering substances on the response. However our system was found to be free from any significant interference due to the presence of AA, UA, EP, aspartic acid, L-Dopa or glucose. Moreover, the modified electrode could be used for real samples. The preparation for the modification of the electrode was also easier and faster (a few minutes) than all the previous reports. This work thus supersedes all previous work in almost all respects.

\section{Conclusions}

A novel chemical sensor for dopamine was fabricated based on a nano-porous PPyox template with deposited Ag nanoparticles. Analysis by EIS revealed a lowering of charge transfer resistance by many 
fold due to the modification of the electrode. This modified electrode exhibited a strong electrocatalytic activity towards the oxidation of DA. Moreover, it resolved the signal due to AA from interferences due to UA, EP, L-dopa and glucose, primarily by shifting their oxidation potentials, as shown by the DPV results. Using $\mathrm{CV}$, the detection limit of DA was estimated to be about $0.5 \times 10^{-9} \mathrm{M}$. Due to the synergistic effect of the doped PPyox and Ag nanoclusters, this new electrode system resulted in a better detection limit, and higher sensitivity and selectivity to DA, even in the presence of excess of AA, as compared with other methods reported in the literature. Hence, the most important issues for direct estimation of DA in real samples such as human blood serum have been resolved. Mechanisms are proposed to explain the variation in response due to $\mathrm{pH}$, the high response to $\mathrm{AA}$ and the reduction of signal due to interfering substances. This PPyox film electrode in combination with metal nanoparticles provides a potentially valuable tool for very efficient and highly selective electrochemical sensor design.

\section{Acknowledgement:}

The author (SS) is indebted to DST (INSPIRE), New Delhi for her fellowship. The authors acknowledge Bose Institute, Kolkata for providing assistance in characterization of nano-particles and polymer.

\section{References:}

[1] R.M. Wightman, L.J. May, A. C. Michael (1988) Detection of dopamine dynamics in the brain, Anal. Chem 60 : 769A-779A.

[2] P. Damier, E.C. Hirsch, Y.; Agid, A.M. Graybiel (1999) The substantia nigra of the human brain. II. Patterns of loss of dopamine-containing neurons in Parkinson's disease, Brain 122: 1421-1436. 
[3] A. Sawa, S.H. Snyder (2002) Schizophrenia: diverse approaches to acomplex disease, Science 296: 692-695.

[4] J.W. Mo, B. Ogorevc (2001) Simultaneous measurement of dopamine and ascorbate at their physiological level using voltammetric microprobe based on over oxidized poly (1,2phenylenediamine)-coated carbon fiber, Anal. Chem 73: 1196-1202.

[5] F.B. Salem (1987) Spectrophotometric and titrimetric determination of catecholamines, Talanta 34 : $810-812$.

[6] S. Sarre, Y. Michotte, P. Herregodts, D. Deleu, N. De Klippel, G. Ebinger (1992) Highperformance liquid chromatography with electrochemical detection for the determination of levodopa, catecholamines and their metabolites in rat brain dialysates, J. Chromatogr 575: 207-212.

[7] P. Sarkar, I E. Tothill, S. J. Setford, and A. P. F. Turner (1999) Screen-printed amperometric biosensors for the rapid measurement of 1- and d-amino acids, Analyst $124: 865-870$.

[8] R.D. O’Neill (1994) Microvoltammetric techniques and sensors for monitoring neurochemical dynamics in vivo. A review, Analyst 119: 767-769.

[9] A. C. Micheal, J. B. J. Justice (1987) Oxidation of dopamine and 4-methylcatechol at carbon fiber disk electrodes, Anal Chem 59: 405-410.

[10] T. Zetterstrom, T. Sharp, C.A. Marsden, U. Ungerstedt (1983) In vivo measurement of dopamine and its metabolites by intracerebral dialysis:change after d-amphetamine, J. Neurochem 41: 1769-1773.

[11] T. Luczak (2008) Preparation and characterization of the dopamine film electrochemically deposited on a gold template and its applications for dopamine sensing in aqueous solution, Electrochim. Acta 53: 5725-5731. 
[12] P. Capella, B. Ghasemzadeh, K. Mitchell, R.N. Adams (1990) Nafion coated carbon fibre electrodes for neurochemical studies in brain tissue, Electroanalysis 2: 175-182.

[13] J. Tashkhourian, M.R. Hormozi Nezhad, J. Khodavesi, S. Javadi (2009) Silver nanoparticles modified carbon nanotube paste electrode for simultaneous determination of dopamine and ascorbic acid, J. Electroanal. Chem 633: 85-91.

[14] Shah R. Ali, Rishi R Yufeng Ma, Parajuli, Yetunde Balogun, Y.C. Warren Lai, He. Huixin (2007) A nonoxidative sensor based on a self-doped polyaniline/carbon nanotube composite for sensitive and selective detection of the neurotransmitter dopamine, Anal. Chem 79: 2583-2587.

[15] G. Jin, Y. Zhang, W. Cheng, Poly (2005) ( $p$-aminobenzene sulfonic acid)-modified glassy carbon electrode for simultaneous detection of dopamine and ascorbic acid, Sens. Actuator B: Chem 107: 528534.

[16] S. Senthil Kumar, J. Mathiyarasu, K. Lakshminarasimha Phani (2005) Exploration of synergism between a polymer matrix and gold nanoparticles for selective determination of dopamine, J. Electroanal. Chem 578: 95-103.

[17] Li. Jing, Lin. Xiangqin (2007) Simultaneous determination of dopamine and serotonin on gold nanocluster/overoxidized-polypyrrole composite modified glassy carbon electrode, Sensors and Actuators B 124: 486-493. 
[18] Wang. Ai-Jun, Feng. Jiu-Ju, Li. Yong-Fang, Xi. Jun-Lan, Dong. Wen-Ju (2010) In-situ decorated gold nanoparticles on polyaniline with enhanced electrocatalysis towards dopamine, Microchim Acta 171: 431-436.

[19] P. Shakkthivel, S.M. Chen (2007) Simultaneous determination of ascorbic acid and dopamine in the presence of uric acid on ruthenium oxide modified electrode, Biosens. Bioelectron 22: 1680-1687.

[20] Lin a. Liqing, Chen. Jinghua, Yao. Hong, Chen. Yuanzhong, Xinhua. Yanjie Zheng (2008) Simultaneous determination of dopamine, ascorbic acid and uric acid at poly (Evans Blue) modified glassy carbon electrode, Bioelectrochemistry 73: 11-17.

[21] M. Zhang , C. Liao , Y. Yao , Z. Liu , F. Gong, and F. Yan (2014) High performance dopamine sensors based on whole grapheme solution-gated transistors, Adv. Funct. Mater 24: 978-985.

[22] S. Abdollah, A. Kamaleddin, K. Gholam-Reza (2004) Amperometric Detection of Dopamine in the Presence of Ascorbic Acid Using a Nafion Coated Glassy Carbon Electrode Modified with Catechin Hydrate as a Natural Antioxidant, Microchim. Acta 144: 161-169.

[23] J. Weng, J. Xue, J. S. Wang Ye, H. Cui, F. S. Sheu, Q. Zhang (2005) Gold clusters sensors formed electrochemically at boron doped diamond electrodes: Detection of dopamine in the presence of ascorbic acid and thiols, Adv. Fuct. Mater 15: 639-647.

[24] Z. Gao, D. Yap, Y. Zhang (1998) Voltammetric Determination of Dopamine in a Mixture of Dopamine and Ascorbic Acid at a Deactivated Polythiophene Film Modified Electrode, Anal. Sci 14: 1059-1064.

[25] K. Pihel, Q.D. Walker, R.M. Wightman (1996) Overoxidized polypyrrole-coated carbon fiber microelectrodes for dopamine measurements with fast-scan cyclic voltammetry. Anal. Chem 68 :20842089. 
[26] V.S. Vasantha, S.M. Chen (2006) Electrocatalysis and simultaneous detection of dopamine and ascorbic acid using poly(3,4-ethylenedioxy)thiophene film modified electrodes, J. Electroanal. Chem 592: 77-87.

[27] W. Kristensen, W. G. Kuhr, R. M. Wightman (1987) Temporal characterization of perfluorinated ion exchange coated microvoltammetric electrodes for in vivo use, Anal. Chem 59: 1752-1757.

[28] L. Jiang, Q. Xie, Z. Li, Y. Li, S. Yao (2005) A Study on Tannic Acid-doped Polypyrrole Films on Gold Electrodes for Selective Electrochemical Detection of Dopamine , Sensor 5: 199-208.

[29] T. D. Chung, R.A. Jeong, S. K. Kang, H. C. Kim (2001) Reproducible fabrication of miniaturized glucose sensors: preparation of sensing membranes for continuous monitoring, Biosens. Bioelectron 16: 1079-1087.

[30] S. Cosnier (2003) Biosensors based on electropolymerized films: new trends, Anal. Bioanal. Chem 377: 507-520.

[31] D. Hemández-Santos, M.B. González-García, A.C. García (2002) Metal-Nanoparticles Based Electroanalysis, Electroanalysis 14: 1225-1235.

[32] S. Shrivastava , T. Bera, A. Roy, G. Singh, P. Ramachandrarao, D. Dash (2007) Characterization of enhanced antibacterial effects of novel silver nanoparticles, Nanotechnology 18: 225103-225113.

[33] H. Yi, L.Q. Wu, W.E. Bentley, R. Ghodssi, G.W. Rubloff, J.N. Culver, G.F. Payne (2005) Biofabrication with chitosan, Biomacromolecules 6: 2881-2894.

[34] H.Z. Huang, Q. Yuan, X.R. Yang (2004) Preparation and characterization of metal-chitosan nanocomposites, Colloids Surf. B 39: 31-37. 
[35] W. Zhong, S. M. Liu, X. H. Chen, Y. X. Wang, W. T. Yang (2006) High-Yield Synthesis of Superhydrophilic Polypyrrole Nanowire Networks, Macromolecules 39 : 3224-3230.

[36] C.G. Wallace, G. M. Spinks, L.A. P. Kane-Maguire, P. R.Teasdale (2003) Conductive Electroactive Polymers: Intelligent Materials Systems, CRC Press, 237.

[37] J. Wang, S. P. Chen, M. S. Lin (1989) Use of different electropolymerization conditions for controlling the size-exclusion selectivity at polyaniline, polypyrrole and polyphenol films, J. Electroanal. Chem 273: 231-242.

[38] V. Ganesh, S.K. Pal, S. Kumar, V. Lakshminarayanan (2006) Self-assembled monolayers (SAMs) of alkoxycyanobiphenyl thiols on gold-A study of electron transfer reaction using cyclic voltammetry and electrochemical impedance spectroscopy, Journal of Colloid and Interface Science 296: 195-203

[39] Roy. P R, T. Okajima, T. Ohsaka (2003) Simultaneous electroanalysis of dopamine and ascorbic acid using poly (N, N-dimethylaniline)-modified electrodes, Bioelectrochem 59: 11-19.

[40] U.E. Majewska, K. Chmurski, K. Biesiada, A.R. Olszyna, R. Bilewic (2006) Dopamine Oxidation at Per(6-deoxy-6-thio)- $\alpha$-Cyclodextrin Monolayer Modified Gold Electrodes, Electroanalysis 18: 14631470.

[41] A.J. Bard, L.R. Faulkner (2001) Electrochemical Methods: Fundamentals and Applications, Vol 3, Wiley, New York, 2nd edn. p. 114.

[42] G. Zou, Z. Liu, C (1997) Wang, Flow injection analysis methods for determination of diffusion coefficients, Anal. Chim. Acta 350: 359-363.

[43] R. N. Hegde, B. E. Kumara Swamy, N. P. Shetty, S. T. Nandibewoor (2009) Electro-oxidation and determination of gabapentin at gold electrode, J. Electroanal. Chem 635: 51-57. 
[44] M.E. Swatz, I.S. Krull, Analytical Method Development and Validation, Marcel Dekker, NewYork, 1997.

[45] F. P. Beck, Braun, Oberst, M. Ber. Bunsenges (1987) Organic Electrochemistry in the Solid StateOveroxidation of Polypyrrole, Phys. Chem 91: 967-974.

[46] A.W. Sternson, R. McCreery, B. Feinberg, R. N. Adams (1973) Electrochemical studies of adrenergic neurotransmitters and related compounds, J.Electroanal. Chem 46: 313-321.

\section{Captions for Figures}

Fig. 1 : TEM image of Ag Nanoparticles (a) UV-vis spectra of Ag Nanoparticles (b) and $\mathrm{X}$-ray diffraction pattern of chitosan and chitosan-Ag nanoparticles (c)

Fig. 2: FTIR spectra of (a) Pristine PPY and (b) PPY-PTSA film

Fig. 3: SEM image of electropolymerised PPy film without PTSA (A); with PTSA (B) and Overoxidised (C)

Fig. 4: Nyquist plot of modified electrode in $0.1 \mathrm{mM}$ DA at PBS/pH 7 at the oxidation potential $(200 \mathrm{mV})$ and bare electrode (inset), Frequency range: $0.1-100000 \mathrm{~Hz}$

Fig. 5: CVs for modified electrode at various buffered $\mathrm{pH}$ values in $1 \mathrm{mM} \mathrm{DA}$ (Inset: plot of $\mathrm{E}^{\mathrm{o}^{\prime}}$ vs $\mathrm{pH}$ )

Fig. 6: CVs of $1 \mathrm{mM}$ DA in $\mathrm{pH} 7$ phosphate buffer recorded at different scan rate $10-150 \mathrm{mVs}^{-1}$ (Inset: relationship between square root of scan rate and peak current)

Fig. 7: Cyclic voltammograms obtained at modified electrode (in absence of DA) and bare Pt (inset), PPyox-PTSA/Pt, PPyox-PTSA/Ag-NP/Pt in the presence of $1 \mathrm{mM}$ DA at a scan rate of 
$40 \mathrm{mVs}-1$ in $50 \mathrm{mM}$ pH 7.0 phosphate buffer

Fig. 8: Cyclic voltammograms of modified electrode for different concentration at $40 \mathrm{mVs}^{-1}$ scan rate in 50mM Phosphate buffer (Inset: calibration plot for 10 to $120 \mathrm{nM}$ )

Scheme 1: Mechanism of Dopamine oxidation

Fig. 9: Current response obtained at modified electrode for the addition of (a) AA (b) UA (c)

Epinephrine (d) Aspartic acid (e) L-dopa (f) Glucose (g) to (i) DA respectively

Fig. 10: DPV of PPyox-PTSA/Ag NP modified Pt in pH 7 PBS containing (A) $100 \mu \mathrm{M}$ AA, $50 \mu \mathrm{M}$ UA and $100 \mathrm{nM}-0.1 \mu \mathrm{M}$ DA (B) $0.1 \mu \mathrm{M}$ DA \& 10-100 $\mu \mathrm{M}$ AA (c) $0.1 \mu \mathrm{M}$ DA \& 5-50 $\mu \mathrm{M}$ UA

Fig. 11: Stability study of modified electrode (a) \& Reusability (b) in presence of 5mM DA

Fig. 12: Calibration curve of typical current-time response of the PPY/PTSA/AgNP modified pt electrode upon the successive addition of $10 \mu \mathrm{L}$ DA at constant potential $0.25 \mathrm{v}$

\section{Captions for Tables}

Table 1: Impedance value of bare and modified electrode determined from fitted equivalent circuit models 
Table 2: Recovery results obtained for DA in human serum sample at modified electrode

Table 3: Comparison of DA detection of various electrodes modified by different methods 

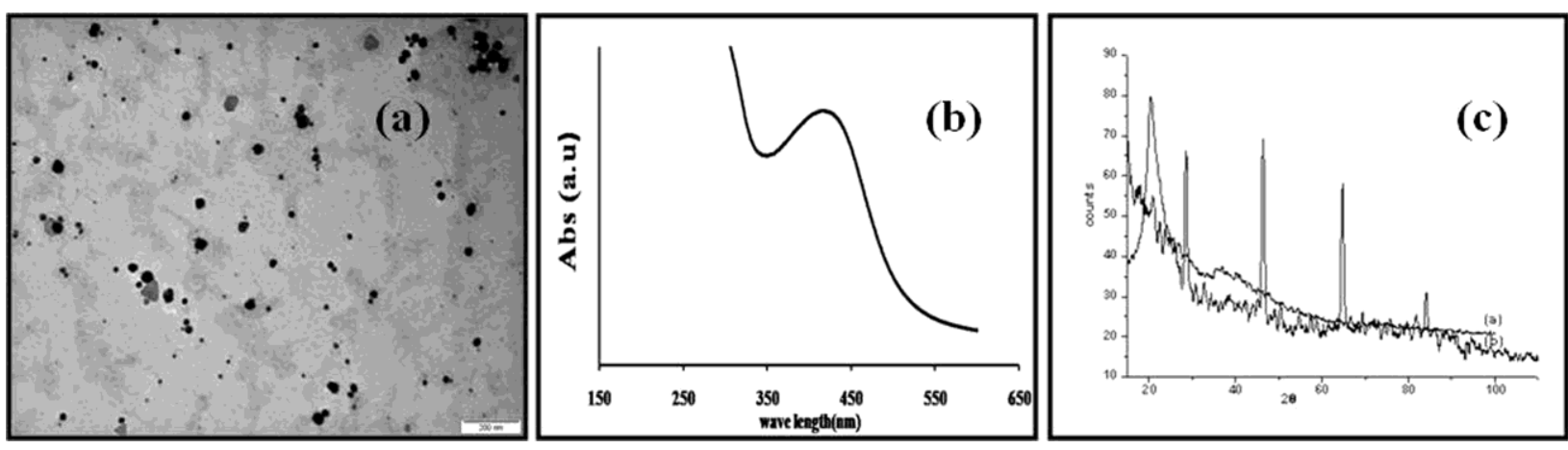

Fig.1
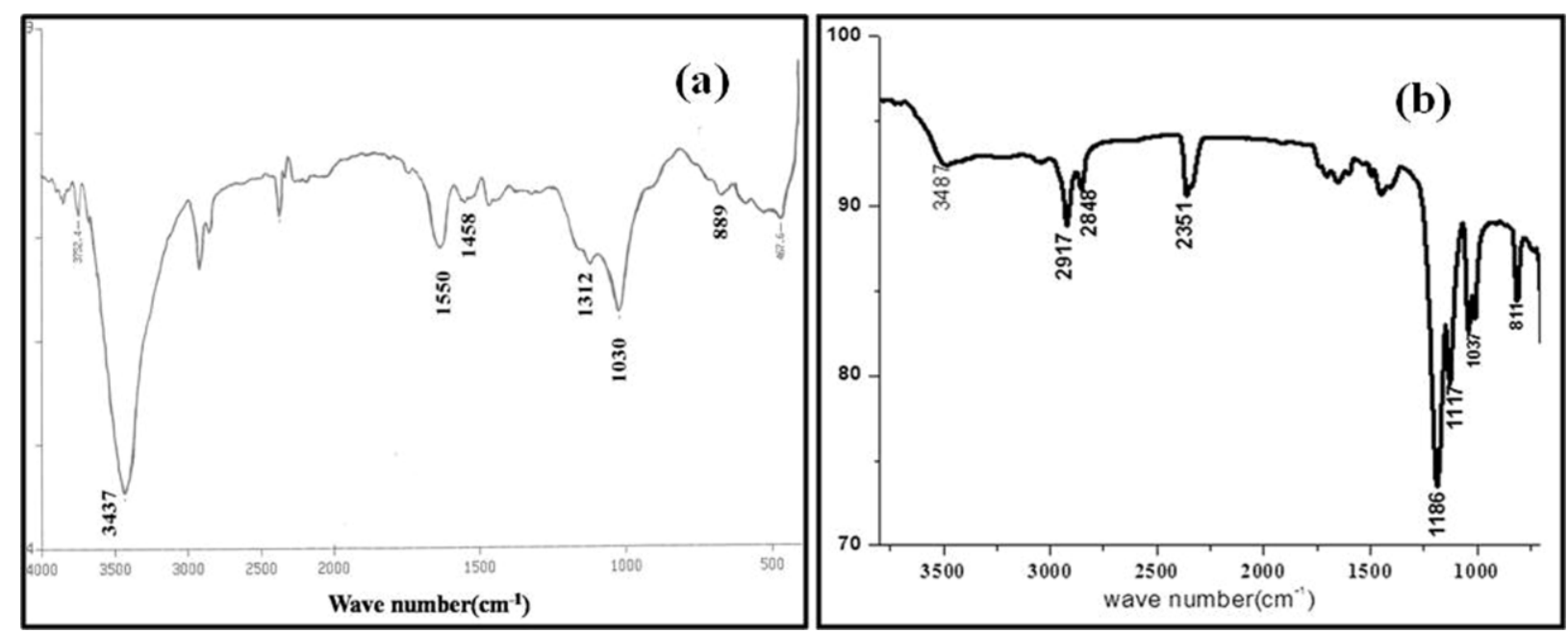

Fig. 2 


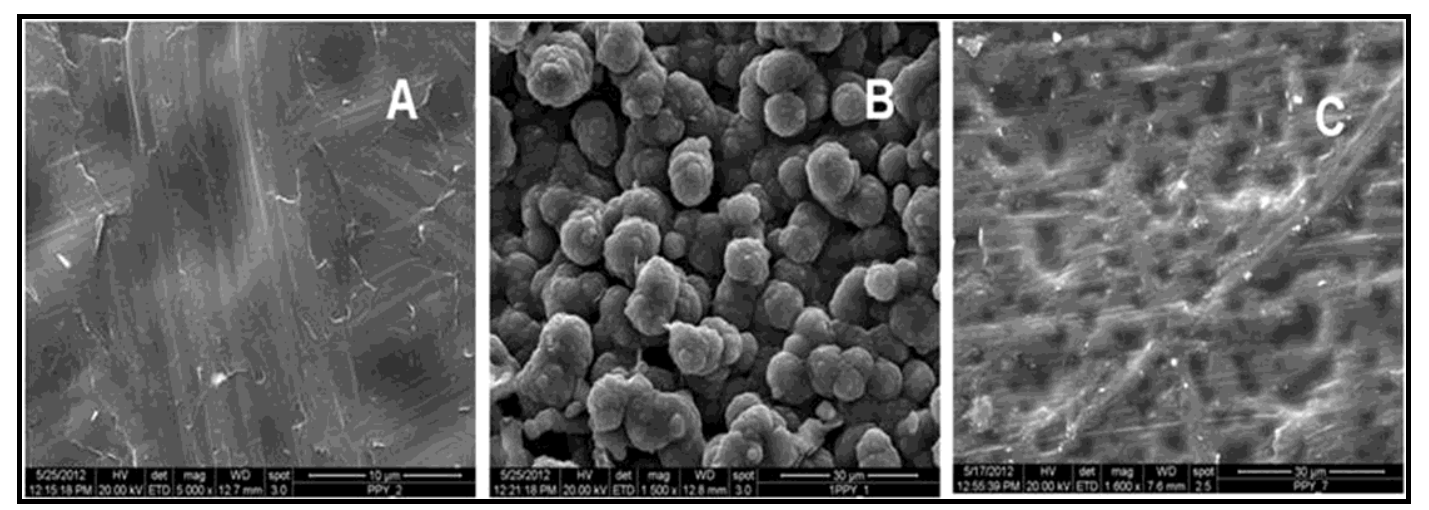

Fig. 3

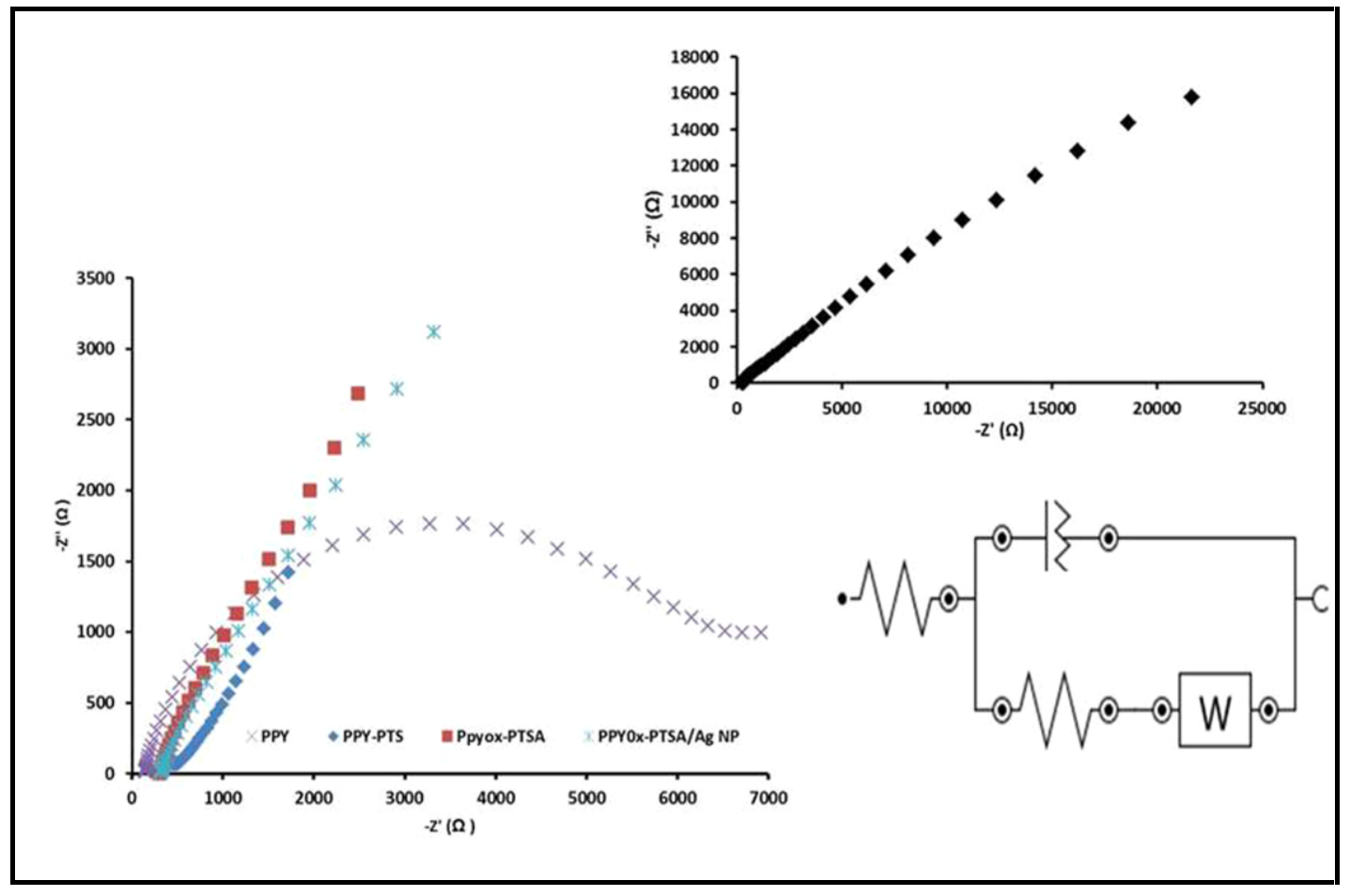

Fig. 4 


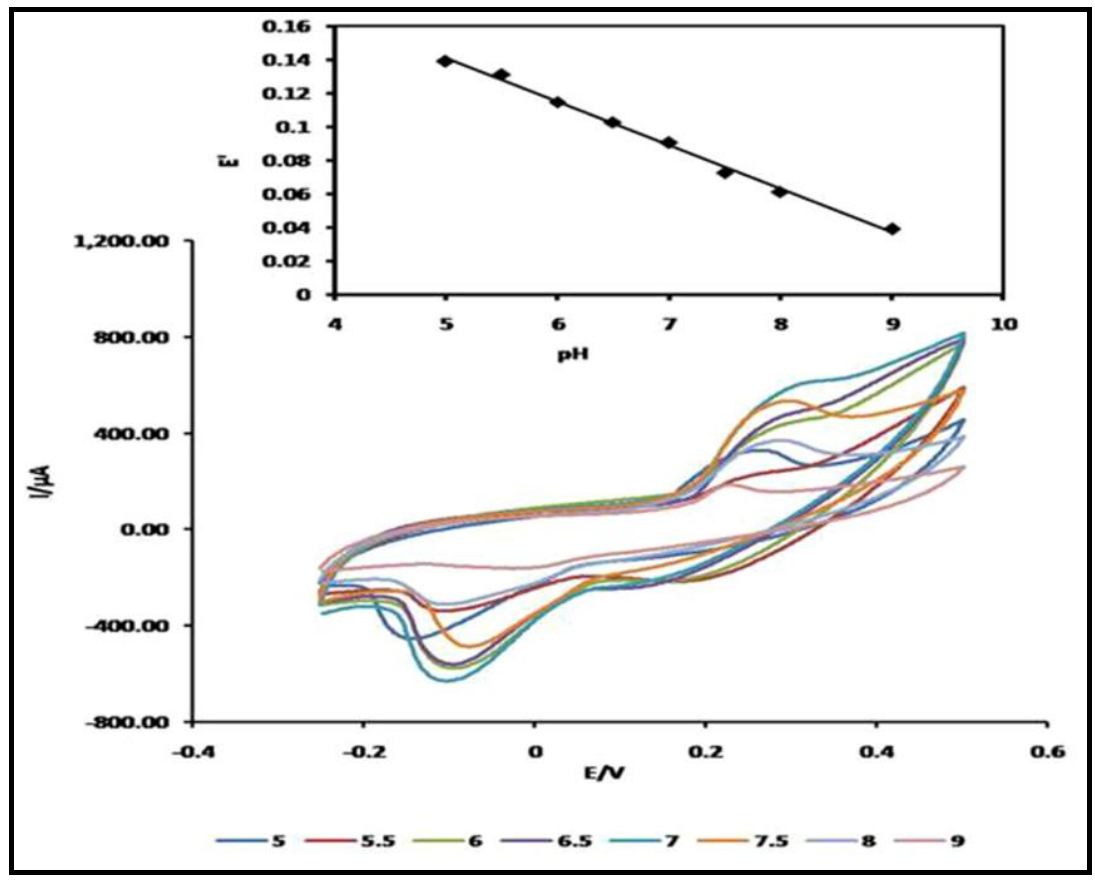

Fig. 5

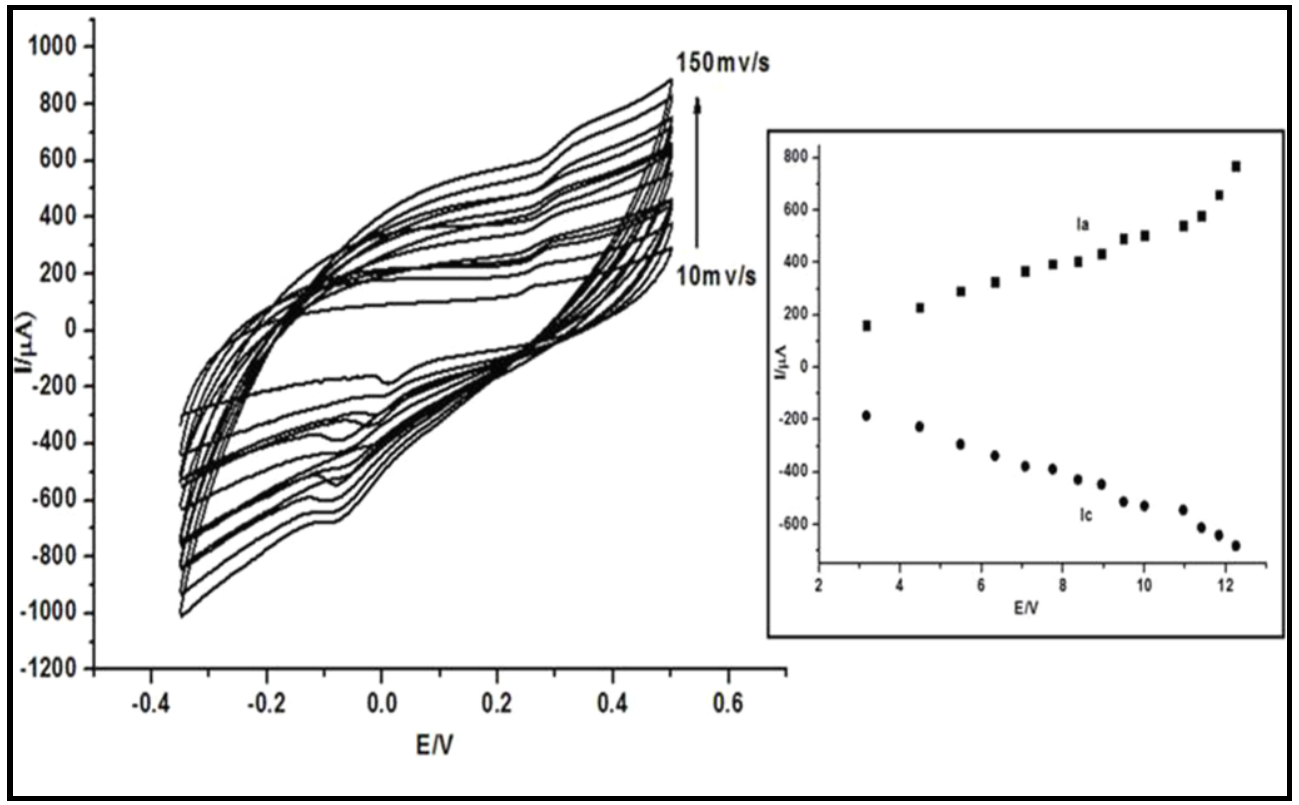

Fig. 6 


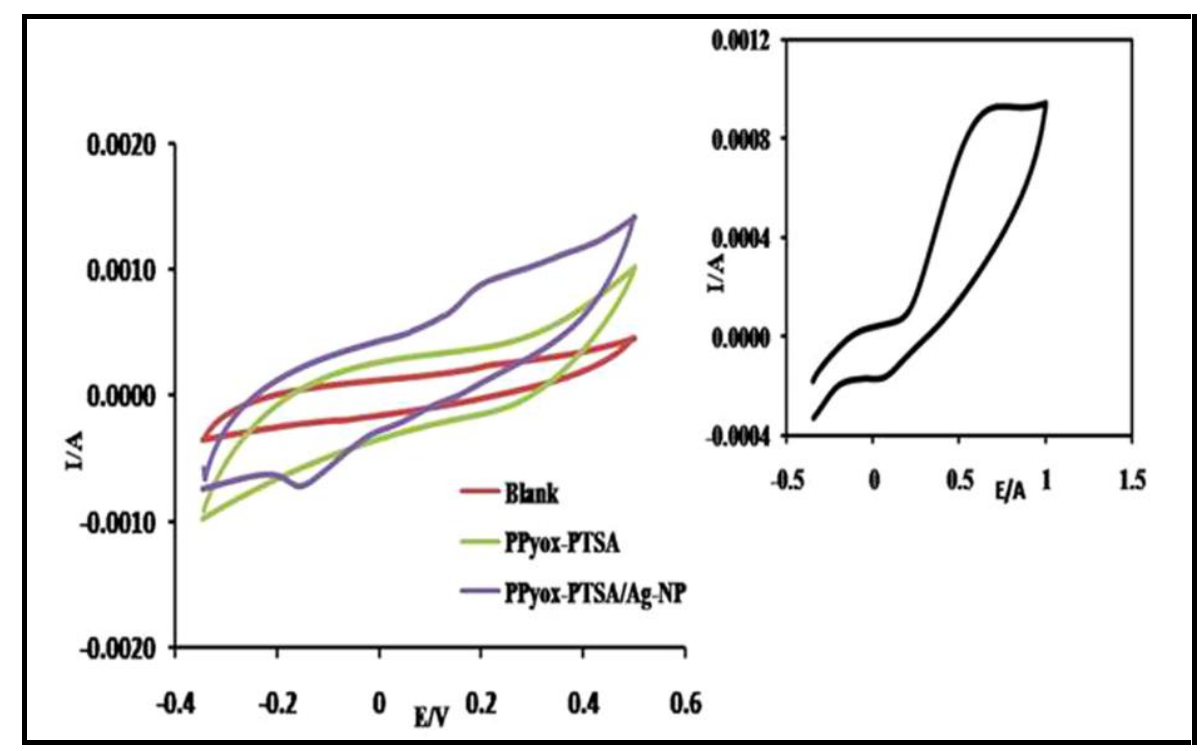

Fig. 7

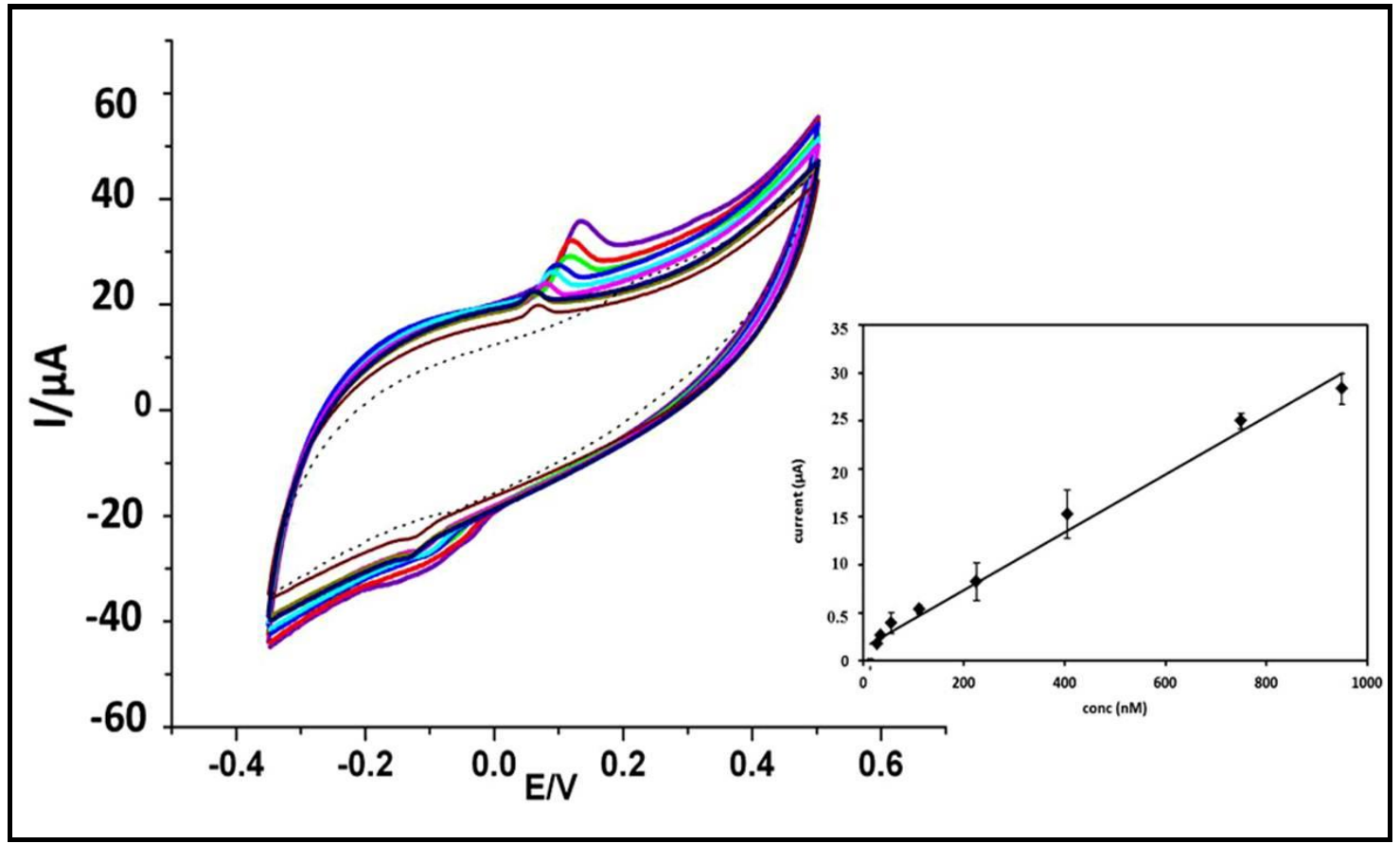

Fig. 8 


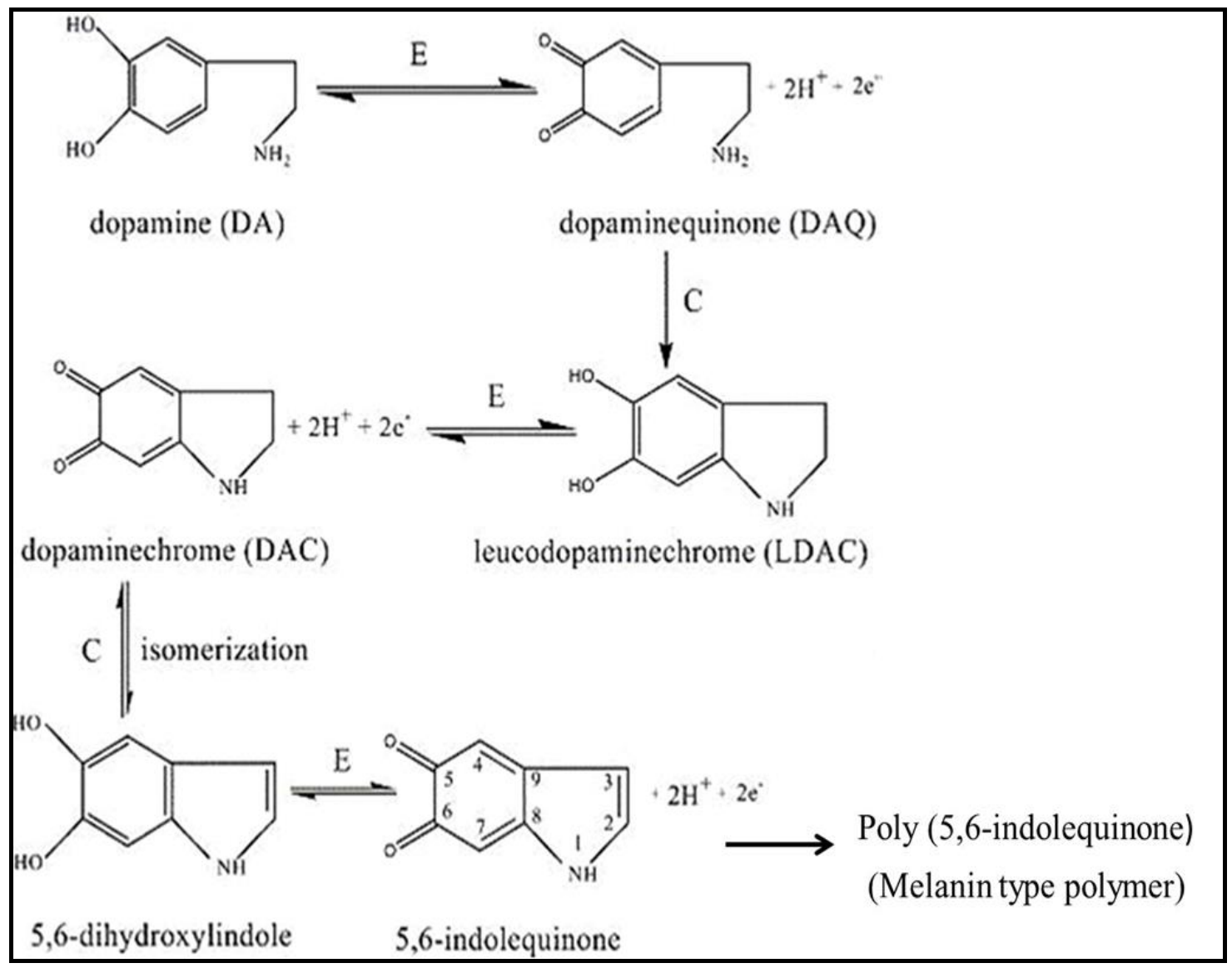

Scheme 1 


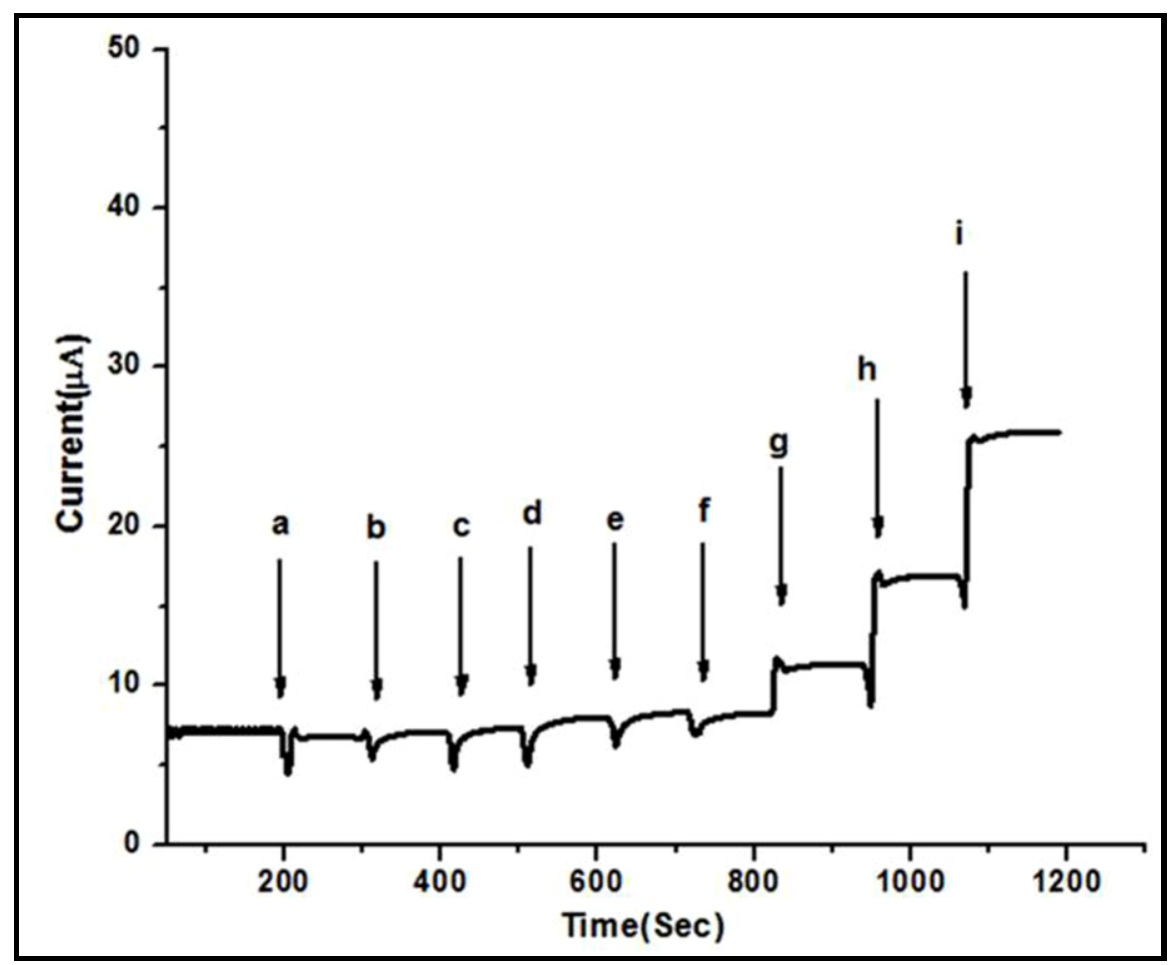

Fig. 9

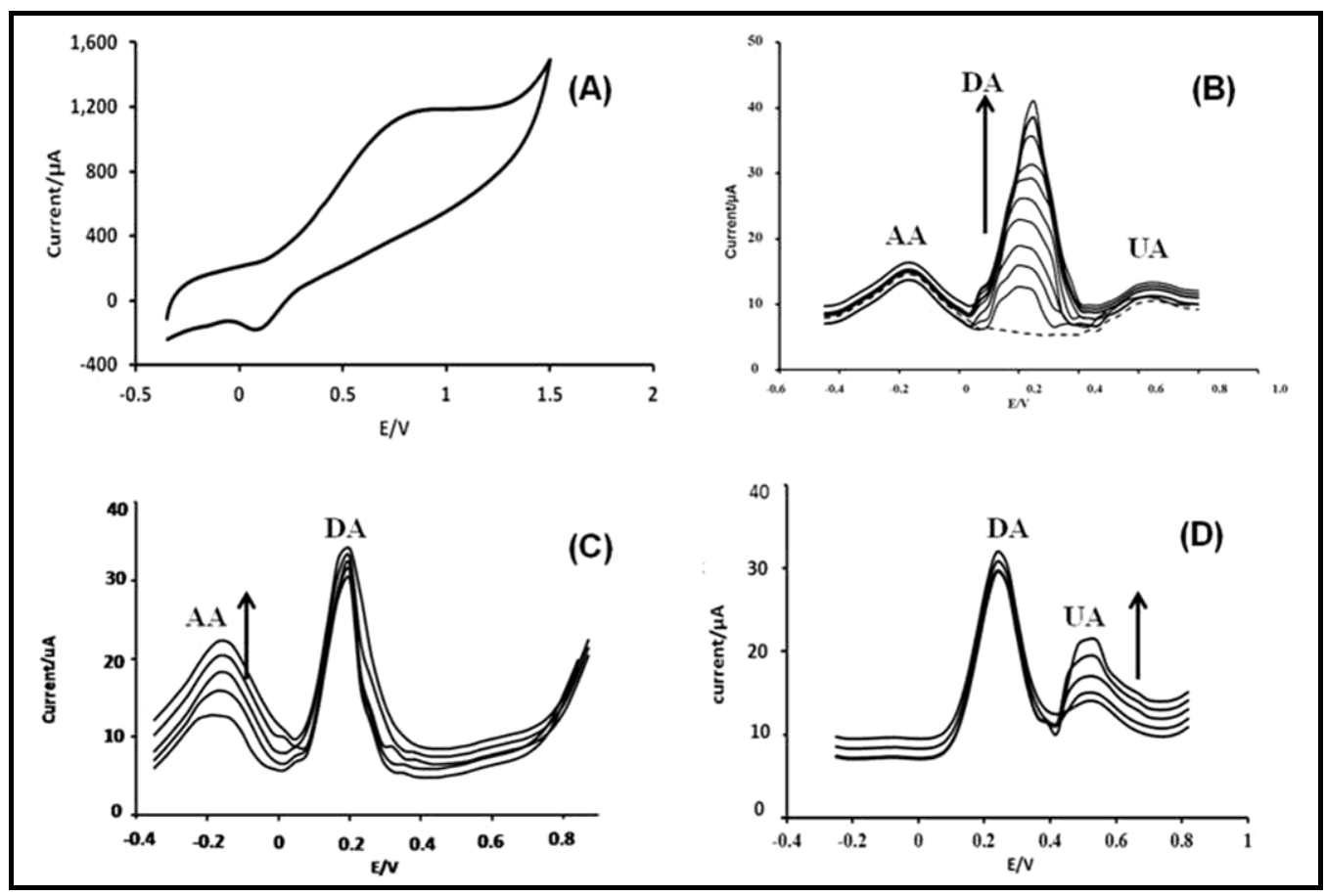

Fig. 10 


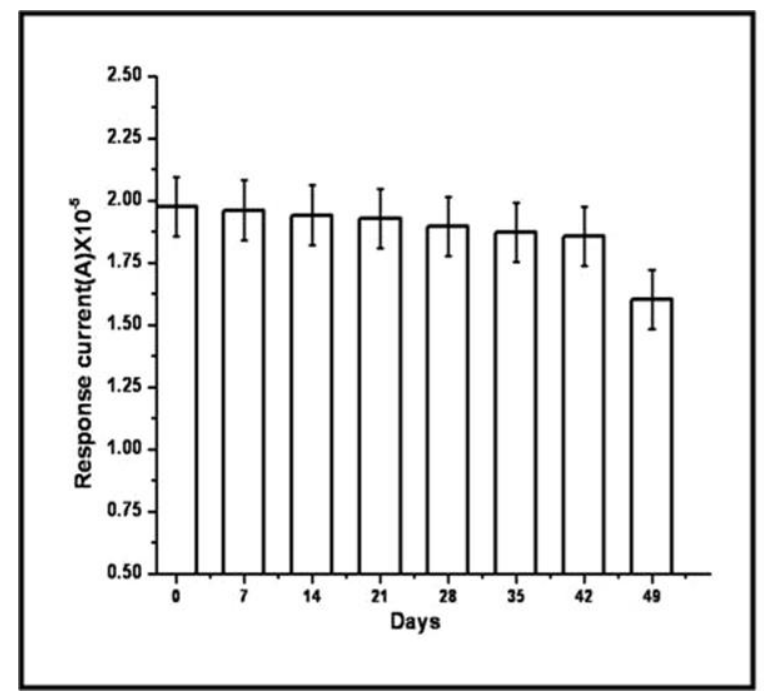

(a)

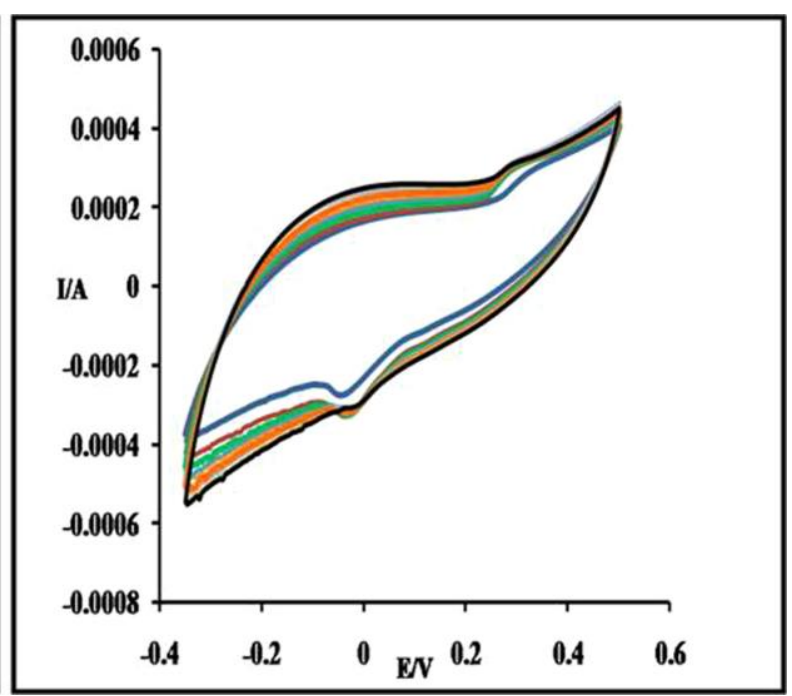

(b)

Fig. 11

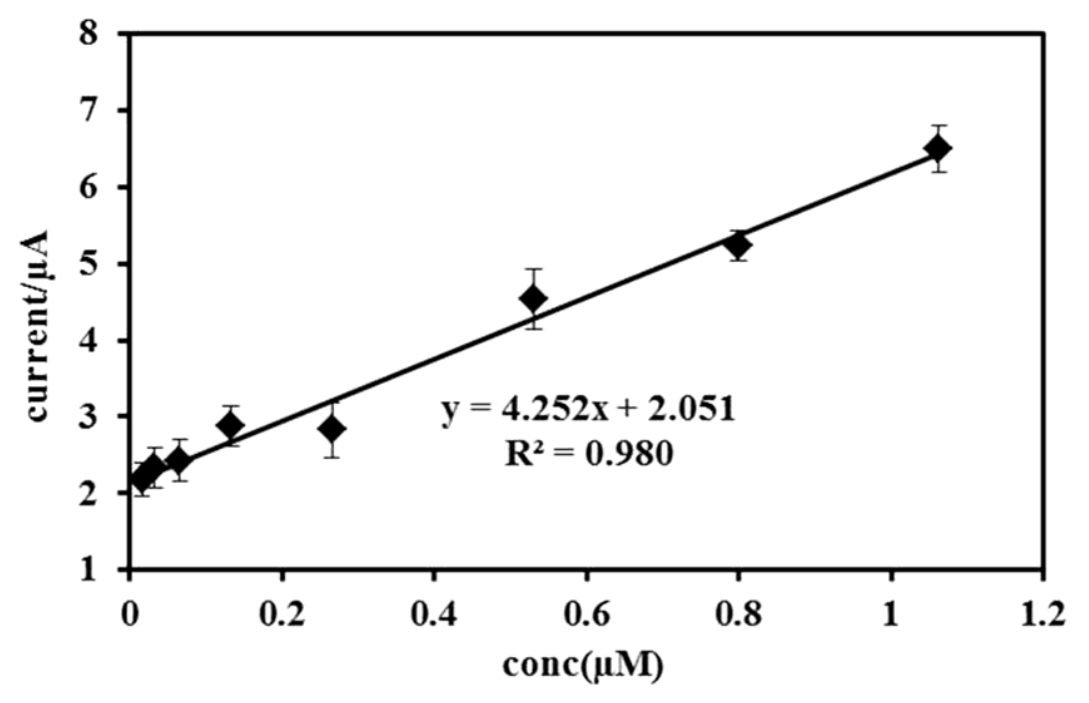

Fig. 12 
Table 1

\begin{tabular}{ccc}
\hline Modified electrode & Ko $_{\mathbf{0}}(\mathrm{cm} / \mathrm{s})$ & Rct \\
\hline Bare electrode & $1.89 \times 10^{-5}$ & $2.19 \mathrm{k} \Omega$ \\
PPy/Pt & $1.78 \times 10^{-5}$ & $5.62 \mathrm{k} \Omega$ \\
PPyox-PTSA/Pt & $2.625 \times 10^{-4}$ & $382 \Omega$ \\
PPyox-PTSA-AgNP/Pt & $4.82 \times 10^{-3}$ & $20.8 \Omega$ \\
\hline
\end{tabular}

Table 2

\begin{tabular}{cccc}
\hline Sample & Spiked $(\boldsymbol{\mu M})$ & Detected $(\boldsymbol{\mu M})$ & Recovery $(\boldsymbol{\%})$ \\
\hline $\mathbf{1}$ & 0.05 & 0.049 & 98 \\
$\mathbf{2}$ & 0.1 & 0.121 & 121 \\
$\mathbf{3}$ & 0.2 & 0.207 & 100.3 \\
$\mathbf{4}$ & 0.25 & 0.235 & 90 \\
$\mathbf{5}$ & 0.3 & 0.309 & 94 \\
$\mathbf{6}$ & 0.5 & 0.457 & 91 \\
\hline
\end{tabular}


Table 3

\begin{tabular}{|c|c|c|c|c|c|c|c|c|}
\hline $\begin{array}{c}\text { Sr } \\
\text { No. }\end{array}$ & $\begin{array}{c}\text { Electrode } \\
\text { Modification }\end{array}$ & $\begin{array}{l}\text { Detection } \\
\text { limit }(M)\end{array}$ & $\begin{array}{c}\text { Linear } \\
\text { range }(M)\end{array}$ & $\begin{array}{c}\text { pH } \\
\text { used }\end{array}$ & Stability & Interferences & Application & Ref \\
\hline 1. & Ag/CNT-CPE & $3.7 \times 10^{-7}$ & $\begin{array}{l}8 . \times 10^{-7}- \\
6.4 \times 10^{-5}\end{array}$ & 2 & - & $\overline{\mathbf{A A}}$ & $\begin{array}{l}\text { Human } \\
\text { serum }\end{array}$ & 13 \\
\hline 2. & Polyaniline/CNT & $0.6 \times 10^{-9}$ & $\begin{array}{l}1 \times 10^{-9}- \\
10 \times 10^{-9}\end{array}$ & 7.4 & - & $\mathbf{A A}$ & - & 14 \\
\hline 3. & PEDOT/Au & $2 \times 10^{-9}$ & - & 7.4 & 30 days & $\mathbf{A A}$ & N.A & 16 \\
\hline 4. & $\begin{array}{c}\text { Au/overoxidised } \\
\text { PPy }\end{array}$ & $1.5 \times 10^{-8}$ & $\begin{array}{c}7.5 \times 10^{-8} \\
-2.0 \times 10^{-5}\end{array}$ & 7 & $\begin{array}{l}\sim 60 \\
\text { days }\end{array}$ & $\begin{array}{c}\text { AA, } \\
\text { Serotonin }\end{array}$ & $\begin{array}{l}\text { Human } \\
\text { serum }\end{array}$ & 17 \\
\hline 5. & PANI/Au & $0.8 \times 10^{-6}$ & $\begin{array}{l}3 \times 10^{-6}- \\
115 \times 10^{-6}\end{array}$ & 4 & - & - & N.A & 18 \\
\hline 6. & $\begin{array}{l}\text { Evans blue } \\
\text { modified }\end{array}$ & $2.5 \times 10^{-7}$ & $\begin{array}{l}1.0 \times 10^{-6}- \\
3.0 \times 10^{-5}\end{array}$ & 4.5 & - & $\mathbf{A A}, \mathbf{U A}$ & DHI & 20 \\
\hline 7. & $\begin{array}{c}\text { Graphene } \\
\text { solution gated }\end{array}$ & $\leq 1 \times 10^{-9}$ & - & - & - & $\begin{array}{c}\text { Glucose, AA, } \\
\text { UA }\end{array}$ & - & 21 \\
\hline 8. & $\begin{array}{c}\text { Nafion/Catechin } \\
\text { Hydrate }\end{array}$ & $11 \times 10^{-9}$ & $\begin{array}{r}100 \times 10^{-9} \\
-0.1 \times 10^{-3}\end{array}$ & 7 & 28days & $\mathbf{A A}, \mathbf{U A}$ & $\begin{array}{l}\text { Plasma } \\
\text { \& Urine }\end{array}$ & 22 \\
\hline 9. & Boron doped & $1 \times 10^{-9}$ & $\begin{array}{l}1 \times 10^{-8} \\
1 \times 10^{-5}\end{array}$ & 7.4 & - & $\mathbf{A A}$ & - & 23 \\
\hline 10. & Present Study & $0.5 \times 10^{-9}$ & $\begin{array}{l}10 \times 10^{-9}- \\
120 \times 10^{-9}\end{array}$ & 7 & 42 days & $\begin{array}{c}\text { AA, UA, EP, } \\
\text { Aspertic } \\
\text { acid, L- } \\
\text { Dopa, } \\
\text { Glucose }\end{array}$ & $\begin{array}{l}\text { Human } \\
\text { serum }\end{array}$ & \\
\hline
\end{tabular}




\section{Graphical Abstract}

Interference-free Electrochemical Detection of Nanomolar Dopamine Using Doped Polypyrrole and Silver Nanoparticles

Suparna Saha, Priyabrata Sarkar*, Anthony PF Turner

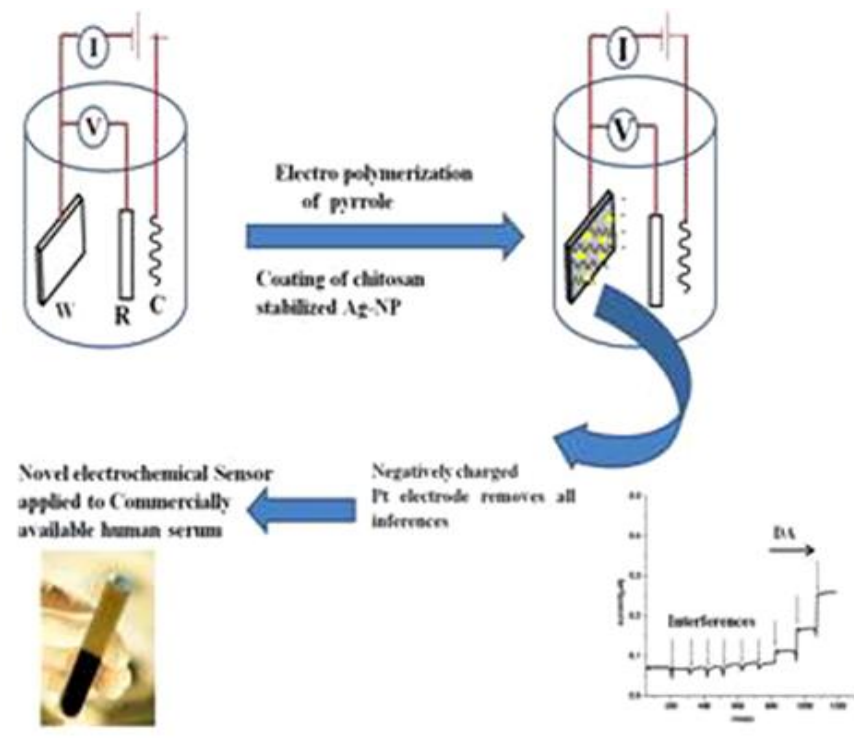




\title{
Selective detection of dopamine by polypyrrole modified platinum electrode via chitosan stabilized silver nanoparticle
}

\author{
Suparna Saha, Priyabrata Sarkar*, Anthony PF Turner** \\ *Biosensor Laboratory \\ Department of Polymer Science and Technology \\ University of Calcutta \\ 92 A.P.C. Road, Kolkata-700 009, India \\ **Biosensors and Bioelectronics Centre \\ IFM-Linköping University \\ S-58183, \\ Linköping \\ Sweden
}

\section{S1. Experimental}

\section{Synthesis of Silver nanoparticles:}

Chitosan (1.25 wt \%) solution was prepared in $1 \%(\mathrm{wt})$ acetic acid solution. The freshly prepared $0.4 \mathrm{mM} \mathrm{AgNO}_{3}$ solution $(1 \mathrm{ml})$ was added drop wise at $95^{\circ} \mathrm{C}$ through a dispenser followed by addition of $100 \mu \mathrm{L}$ of $0.3 \mathrm{M} \mathrm{NaOH}$ in continuous stirring condition. After few minutes, resultant solution started turning yellow indicating the formation of AgNP in the medium. The reaction was allowed to continue for additional 30 minutes and it finally turned brown and the powdered nanoparticles settled at bottom of the beaker. The solid particles were separated by centrifugation and later washed several times with (MQ) water. This was then air dried and stored. The filtrate was treated with concentrated $\mathrm{HCl}$ to check if there were any excess of $\mathrm{Ag}^{+}$remaining in the reaction medium. This test however confirmed that the whole of $\mathrm{AgNO}_{3}$ got reduced to Ag nanoparticles. 


\section{S2. Characterization of silver nanoparticles:}

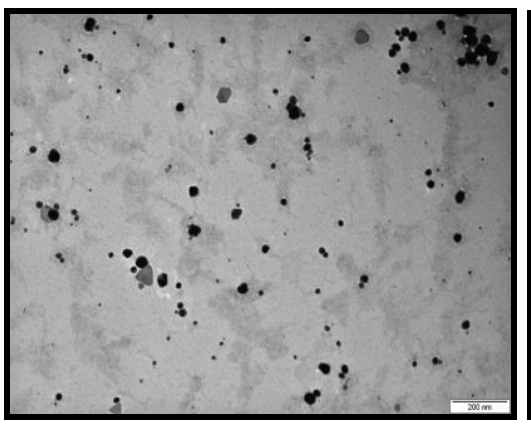

(i)

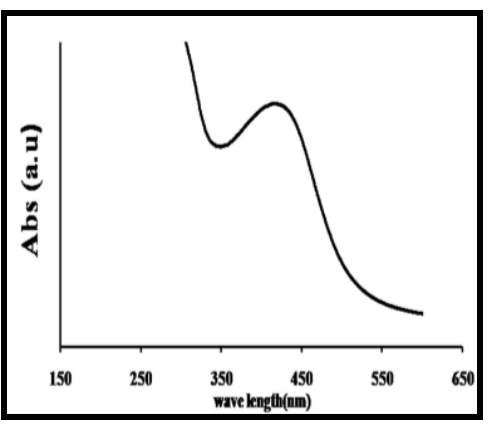

(ii)

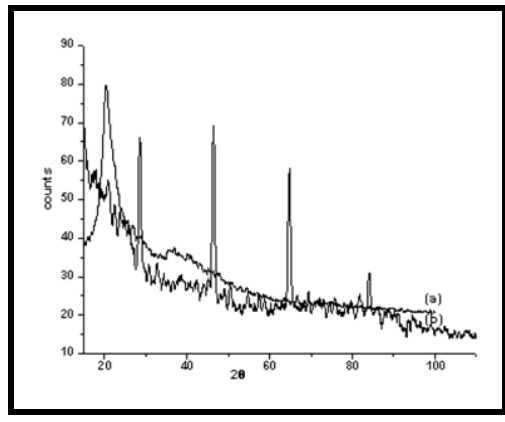

(iii)

Figure S-1: TEM image of Ag Nanoparticles (i) UV-vis spectra of Ag Nanoparticles (ii) and $\mathrm{X}$-ray diffraction pattern of (a) chitosan (b) chitosan-Ag nanoparticles

Silver nanoparticles morphology was observed by transmission electron microscopy (TEM) measurements (Figure S-1-i). This clearly revealed the formation of individual silver nanoparticles. The Ag/chitosan composite nanoparticles were predominantly spherical and polydispersed with diameters in the range of 20 to $25 \mathrm{~nm}$.

A sample of yellow powder of the composite was dispersed in $0.1 \%(\mathrm{~V} / \mathrm{V})$ of acetic acid and the UV-visible spectrum was recorded. The characteristic band of Ag nanoparticles centered at about $420 \mathrm{~nm}$ (Figure S-1-ii). Chitosan-Ag NP composite could be stored up to several months without any discernible precipitation.

The X-ray diffraction pattern of pure chitosan (Figure S-1-iii) showed weak bands at $2 \theta$ values of $20.35^{\circ}$, indicating mostly amorphous nature of the chitosan used in the present study. In the diffractograms of the chitosan-Ag samples (Figure S-3b) the additional peaks appeared at $2 \theta$ with values of around $36^{\circ}(111), 45^{\circ}(200), 55,66$ (220), and $77^{\circ}$ could be recognized as 111, 200, 220, and 311 crystallographic planes of the face-centered cubic Ag crystals, respectively. The peaks confirmed that the main composition of nanoparticles was silver and no other obvious peaks due to the presence of impurities were observed in the XRD patterns. The peak at 22.71 could be due to chitosan with somewhat deviation from $20^{\circ}$ of pristine chitosan. The existence of silver nanoparticles in chitosan fragment was substantiated by this result. 

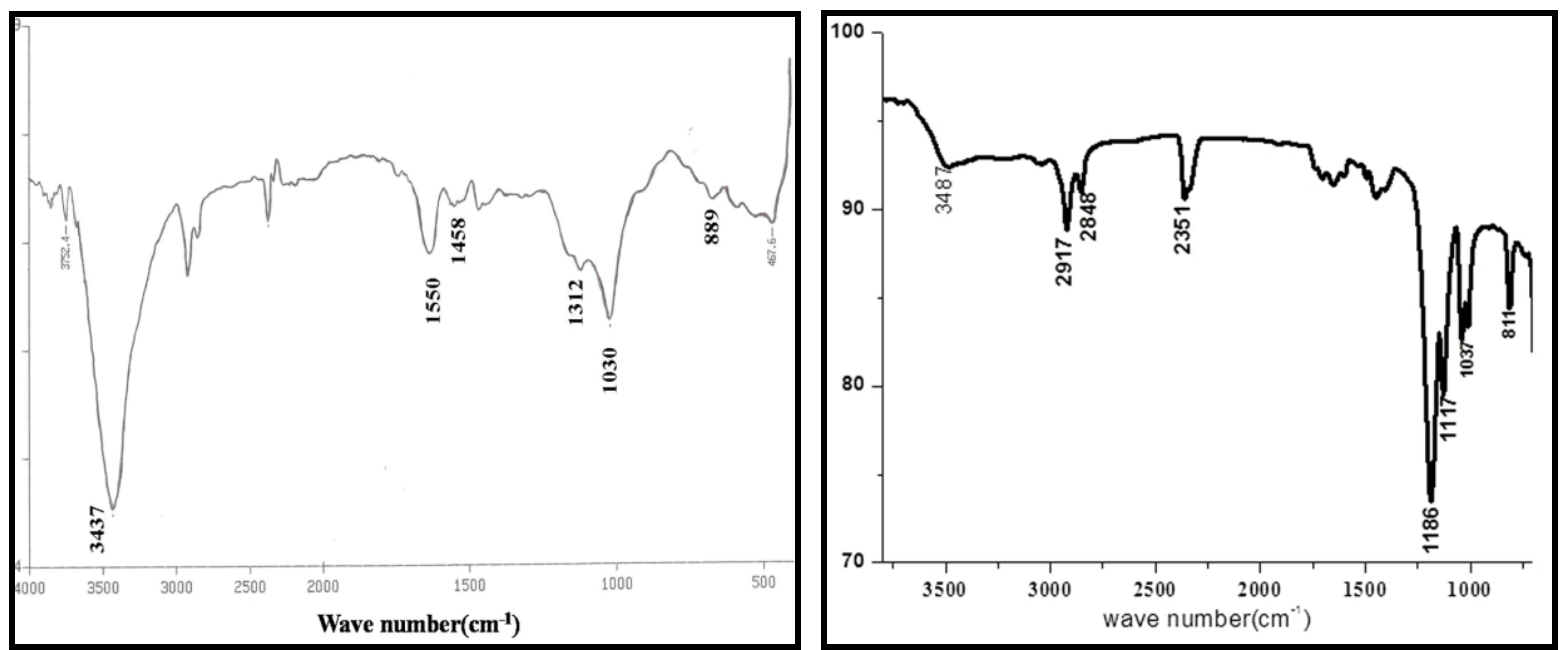

Figure S-2: FTIR spectra of (a) Pristine PPY and (b) PPY-PTSA film

The first step in the electrochemical polymerization of pyrrole is the generation of radical cation. Subsequently chain propagation proceeds by reaction of oligomer radical cations of the monomer, which is present in high concentration in the region of the anode. During the formation, a stoichiometric amount of anions was incorporated into the polymer layer to neutralize the positive charge of the PPy chains. Therefore, the nature of the anions played an important role in conferring the electrochemical properties of the PPy films (shown in scheme S-1).

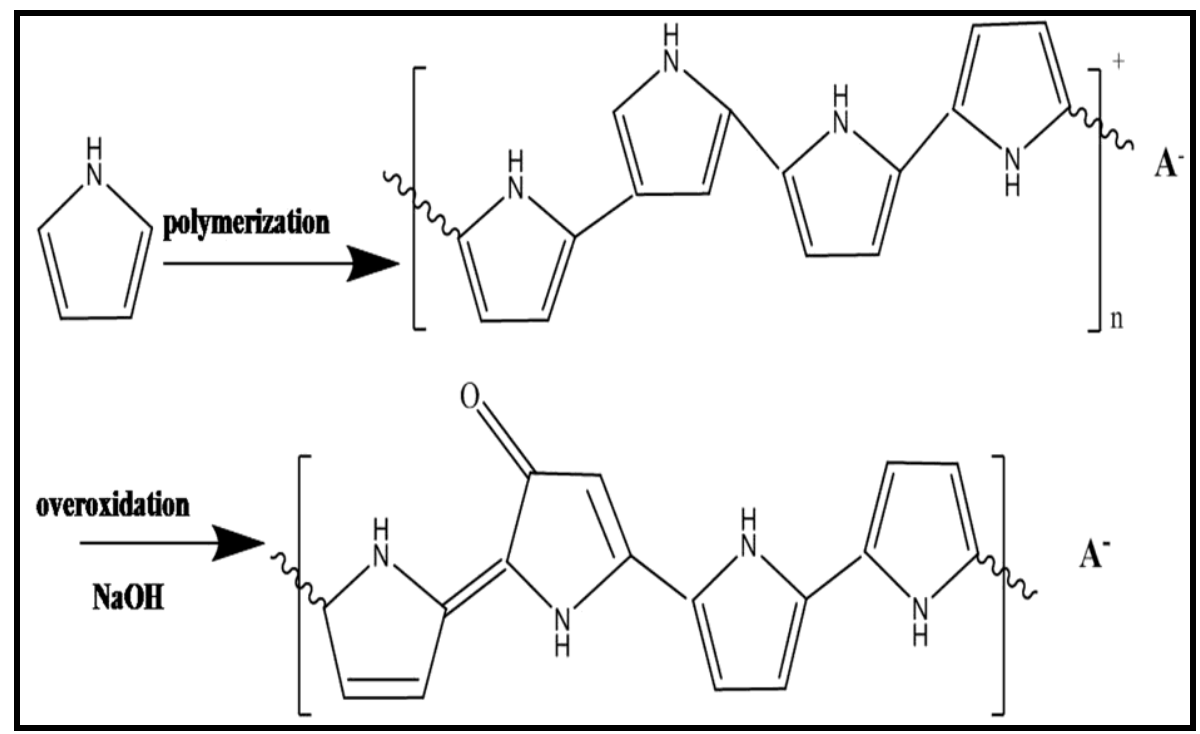

Scheme S-1: Electropolymerization of pyrrole in presence of dopant p-toluene sulfonic acid (A) 


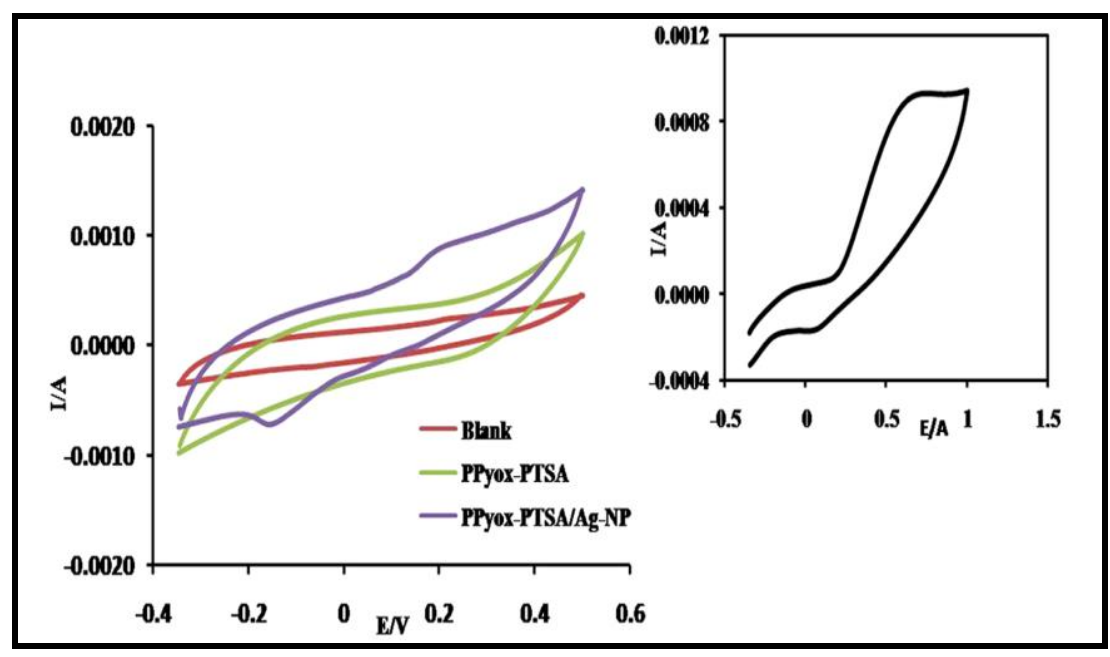

Figure S-3: Cyclic voltammograms obtained at modified electrode (in absence of DA) and bare Pt (inset),PPyox-PTSA/Pt , PPyox-PTSA/Ag-NP/Pt in the presence of $1 \mathrm{mM}$

DA at a scan rate of $40 \mathrm{mVs}^{-1}$ in $50 \mathrm{mM}$ pH 7.0 phosphate buffer

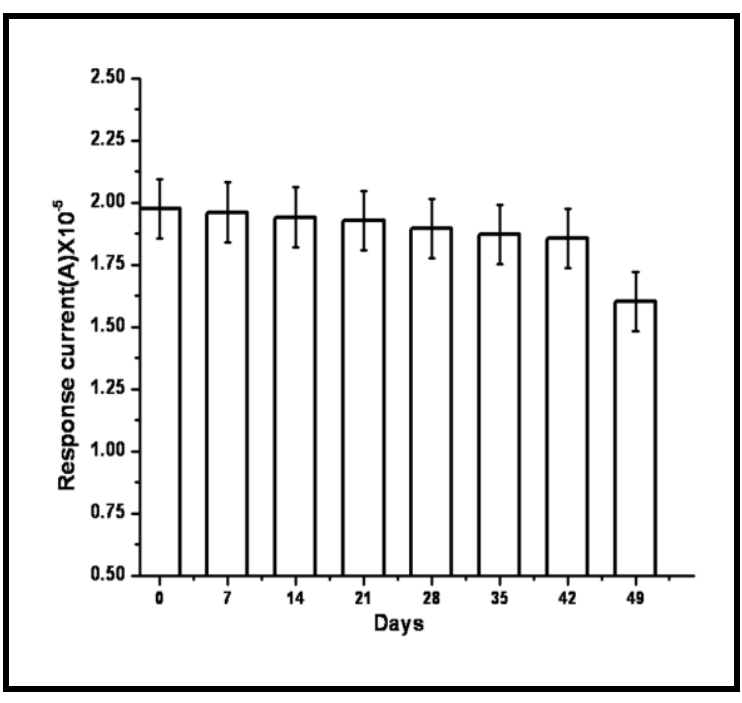

(a)

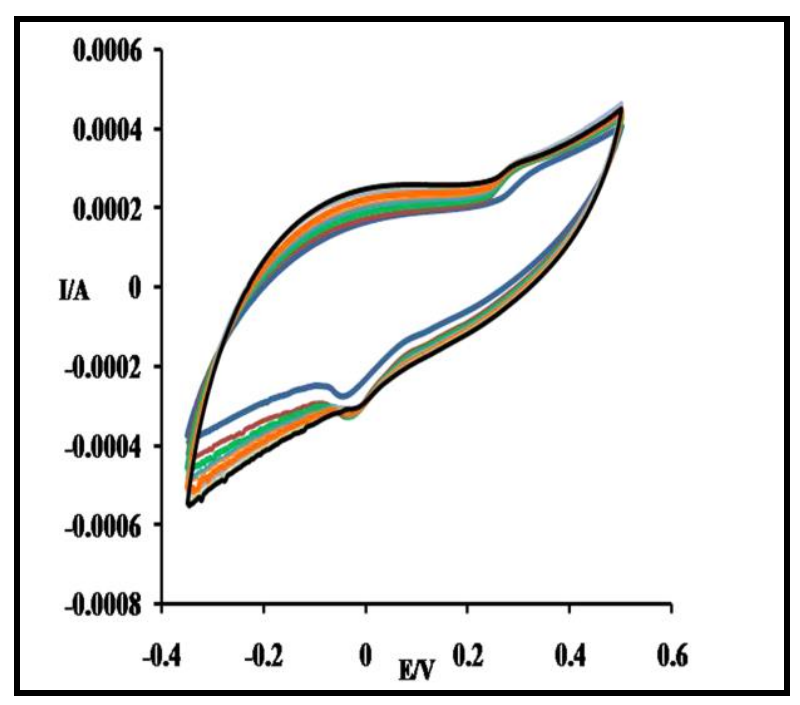

(b)

Figure S-4: Stability study of modified electrode (a) Reusability (b) in presence of $5 \mathrm{mM}$ DA 